\title{
Propaganda Fide frente a la hegemonía hispana: apoyos en las cortes de Madrid y Bruselas a la creación de la congregación de cardenales ${ }^{1}$
}

\author{
Propaganda Fide against the Hispanic hegemony: supports in the courts of Madrid \\ and Brussels to the creation of the Congregation of Cardinals
}

\author{
José Martínez Millán² \\ Universidad Autónoma de Madrid \\ IULCE \\ Esther Jiménez Pablo \\ Universidad Complutense \\ IULCE
}

\begin{abstract}
Resumen: La fundación de la Congregación Propaganda Fide, en 1622, constituyó la supresión de los derechos otorgados por los pontífices del siglo XVI (la expansión y defensa del cristianismo), con los que la Monarquía hispana justificó su expansión territorial. A partir de entonces, la Iglesia de Roma asumió la difusión del catolicismo mediante la predicación y el diálogo con los pueblos, suprimiendo toda violencia prestada por los príncipes aliados.
\end{abstract}

Por supuesto, tal creación resultó una tarea dificultosa para Roma (y su elaboración fue lenta), toda vez que semejante institución cercenaba los intereses en los que se había forjado la Monarquía de Felipe II. Religiosos como Gracián, Vives o Domenico della Scala, así como destacados nobles como el duque de Feria o el marqués de

\footnotetext{
${ }^{1}$ Este artículo ha sido posible gracias a la financiación de la ayuda José Castillejo (2015). Así como al proyecto del Ministerio de Economía y Competitividad HAR2014-52850-C3-2-p: «Maneras de vivir en la España Moderna: Condiciones materiales y formas culturales de lo cotidiana. 3. Cultura, religiosidad y asistencia social»; y al Proyecto «La herencia de los Reales Sitios: Madrid, de Corte a Capital (Historia, Patrimonio y Turismo)» de la Comunidad de Madrid y del Fondo Social Europeo CMM-COURT-TOURIST-ON Ref. H2015/HUM-3415.

2 https://orcid.org/0000-0002-1780-2347

3 https://orcid.org/0000-0002-1658-7024
} 
Leganés, y diversos miembros de la familia real como el cardenal infante Fernando, la infanta Isabel Clara Eugenia o el archiduque Alberto, formaron una red que ayudó en esta dura tarea al Papado, tanto desde la corte de Madrid como desde la de Bruselas, como se analiza en el presente artículo.

Palabras clave: Propaganda Fide; Monarquía hispana; Papado; corte de Madrid; corte de Bruselas.

Abstract: The foundation of the Congregation Propaganda Fide, in 1622, constituted the suppression of the rights which had been granted by the previous pontiffs (the expansion and defense of Christianity) in which the Hispanic Monarchy justified its territorial expansion. From then on, the Church of Rome assumed the expansion of Catholicism through preaching and dialogue with the natives, suppressing all the violence lent by the princes.

Of course, such creation was a difficult task for Rome (and its development was slow), since such an institution limited the interests in which the Monarchy of Philip II had been forged. Religious like Gracián, Vives or Domenico della Scala, as well as outstanding nobles such as the Duke of Feria or the Marquis of Leganés, and various members of the royal family like the Cardinal Infante Fernando, the Infanta Isabel Clara Eugenia or the Archduke Alberto, formed a network that helped the Papacy in this hard task, both from the Madrid court and from the Brussels court, as will be analyzed in this article.

Keywords: Propaganda Fide; Hispanic monarchy; Papacy; court of Madrid; Brussels court.

\section{Introducción}

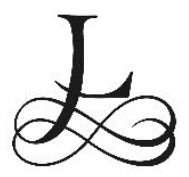

a fundación de la Congregación Propaganda Fide, el 6 de enero 1622, fue el resultado lógico de una larga evolución, en la que Roma recuperó unos privilegios exclusivamente eclesiásticos, que se habían concedido en las denominadas "bulas alejandrinas" a los monarcas hispanos en virtud de la estructura de poder que existía en Europa. Ya en la primera bula Inter Caetera (3 mayo 1493) distinguía dos aspectos de los privilegios que el pontífice concedía a los Reyes Católicos para su expansión a ultramar: los fundamentos de la concesión pontificia (difusión de la fe) y el contenido de la donación (las tierras descubiertas y las que se iban a descubrir, que no estuviesen en manos de cristianos), a cambio de la cristianización de las personas que las habitaran ${ }^{4}$. Es decir, por una parte, definían la condición jurídica en la que se iban a incorporar las tierras

\footnotetext{
4 Juan Manzano Manzano, La incorporación de las Indias a la Corona de Castilla, (Madrid: Ediciones Cultura Hispánica, 1948), pp. 25 y ss. La segunda bula Inter Caetera (datada el 4 de mayo, aunque su verdadera fecha fue 27-30 junio 1493) definía la expansión en torno a un meridiano imaginaria situado cien leguas al occidente de las islas Azores. En la bula Dudum Siquidem (25 septiembre de 1493) ampliaba la donación hecha a los Reyes y a sus sucesores.
} 
descubiertas en el Atlántico a los Reyes Católicos y a sus herederos, con lo que quedaban vinculadas a la Corona de Castilla ${ }^{5}$. Esto es, en virtud del descubrimiento y de la donación papal, las Indias eran un bien ganado por los Reyes Católicos y no un bien heredado ${ }^{6}$. Pero, a diferencia de los bienes ganados, Fernando e Isabel no podían disponer libremente de las islas y tierra firme del mar Océano, pues dichos documentos pontificios prefijaban su destino al haber decidido que ellas se asignaban a los reyes y a sus herederos los reyes de Castilla y León. La reina Isabel dejaba en herencia estos territorios a su hija Juana y Fernando el Católico hacía lo propio cuando murió en 1516. Resulta lógico que fuera Carlos I el primer monarca castellano a quien se titulara como Hispaniarum et Indiarum Rex, según se leía en la moneda acuñada en la Real Casa de la Moneda de México (1535).

Semejantes privilegios, fueron ampliados en la bula Exponi nobis fecisti, expedida el 22 de mayo de $1522^{7}$ por Adriano VI, conocida comúnmente por la bula "omnimoda", que otorgaba a los superiores de las órdenes religiosas poderes amplísimos para la expansión en América, concediendo privilegios que se habían otorgado vivae vocis, sin que -parece- que se registrasen en alguna instancia romana. Esta bula pasó, en buena parte, desapercibida hasta que la Congregación de la Propaganda se enfrentó con la Monarquía hispana con ocasión de la expansión que ésta quería realizar por tierras de China y Japón, en virtud de los privilegios que le otorgaban las bulas Alejandrinas en cuanto al reparto del mundo y que Roma no estaba dispuesta a permitir, alegando que los privilegios otorgados por Alejandro VI solo se referían al continente americano, por lo que los asesores de la Monarquía hispana recurrieron a la bula omnimoda para proceder a su expansión en el Pacífico. Como acabamos de señalar, el documento no se conocía en la Congregación Propaganda Fide, por lo que se pidió a los generales de diversas órdenes religiosas que le remitiesen copia del mismo a la Congregación ${ }^{8}$. Sin duda ninguna, el papado quería recuperar los privilegios (exclusivos de la propia Iglesia) que habían sido regalados a los monarcas hispanos y que, una vez fundada la Congregación Propaganda Fide ocasionaron un continuo enfrentamiento jurisdiccional como sucedía con el placet que ejercía el Consejo de Indias para todo documento eclesiástico que se quería imponer

\footnotetext{
5 Pedro Leturia, Las grandes bulas misionales de Alejandro VI, (Barcelona: Bibliotheca Hispana Missionum, 1930), vol. I. Discrepa de la interpretación de Leturia, Manuel Giménez Fernández, Nuevas consideraciones sobre la historia, sentido y valor de las bulas alejandrinas de 1493 referentes a las Indias, (Sevilla: Escuela de Estudios Hispano-Americanos de la Universidad de Sevilla, 1944), pp. 2-3.

${ }^{6}$ Alfonso García-Gallo y de Diego, "Las Bulas de Alejandro VI y el ordenamiento jurídico de la expansión portuguesa y castellana en África e Indias", Anuario Historia del Derecho Español, 27-28, (1957-58), pp. 462-829; Venancio Carro, La Teología y los teólogos juristas españoles ante la conquista de América, (Salamanca: PPC, 1951); Paulino Castañeda Delgado, La teocracia pontifical y la conquista de América, (Vitoria: Editorial Eset, 1968).

7 Pedro Torres, La Bula Omnimoda de Adriano VI, (Madrid: Instituto Santo Toribio de Mogrovejo, 1948); Cosme Jose Costa, A missiological conflict between Padroado and Propaganda in the East, (Goa: Pilar Publications, 1997).

8 Muy pronto el padre Emmanuel Rodríguez la publicó, Emmanuel Rodríguez, Nova collectio et Compilatio privilegiorum Regularium Mendicatium et non Mendicatum, (Venetiis: 1611).
} 
en territorios americanos, por lo que querían reducir los poderes del patronato regio, dado que era un arma de coacción, incluida en esta figura jurídica ${ }^{9}$.

En relación con estos privilegios se había construido toda la teoría y justificación del monopolio del dominio hispano en América, los principales tratadistas de leyes sobre América, así lo entendieron: Solórzano afirmaba en el libro tercero de la Recopilación de Indias (1680): "Por donación de la Santa Sede Apostólica y otros justos y legítimos títulos, somos señor de las Indias Occidentales, Islas y Tierra Firme del mar Océano, descubiertas y por descubrir, y están incorporadas en nuestra Real Corona de Castilla". Por su parte, Antonio León Pinelo (1595-1660), defendía en su Tratado de confirmaciones reales (Madrid 1630) que: "Las Indias Occidentales, Islas, y tierras adyacentes, desde su descubrimiento, quedaron, y están incorporadas, y unidas a la Corona Real de Castilla"10.

Las consecuencias prácticas de esta doctrina influyeron decisivamente en las relaciones políticas y jurisdiccionales entre la monarquía hispana y el papado. Dado que los monarcas hispanos ejercieron su poder y justificaron su actividad política con pretensiones de monarquía universal, a causa de su hegemonía militar, Roma era consciente de que resultaba inútil tomar cualquier decisión drástica de enfrentamiento con la monarquía, pues, si lo hacía, la monarquía recurría, entre otros métodos, al "recurso de fuerza"11. Por eso, el papado optó por otras vías pacíficas, que se adecuaban a la misión de la Iglesia.

En resumen, desde tiempos de los Reyes Católicos, los monarcas hispanos utilizaron los privilegios papales concedidos para extender el cristianismo a favor de su expansión territorial, lo que significaba una interpretación de la doctrina católica de acuerdo a sus intereses políticos, que llegaba a imponer su jurisdicción sobre la de la Iglesia ${ }^{12}$. Esta pugna jurisdiccional se aceleró a partir del concilio de Trento, cuando Roma llevó a cabo una reforma en el campo ideológico y administrativo que le hizo independiente de todo poder temporal ${ }^{13}$.

\footnotetext{
9 Torres, La Bula Omnimoda de Adriano VI, pp. 54-67; Juan Manzano Manzano, "El sentido misional de la empresa de Indias", Revista de Estudios Políticos, 1 (1941), pp. 108-114.

10 Juan Manzano Manzano, Historia de las recopilaciones de Indias, (Madrid: Ediciones Cultura Hispánica, 1950), pp. 34-39.

11 José Martínez Millán, M. Antonietta Visceglia (dirs.), La Monarquía de Felipe III, (Madrid: Mapfre, 2005), vol. I, pp. 25-50.

12 Antonio Egaña, La teoría del regio vicario español en Indias, (Roma: Analecta Gregoriana, 1958), pp. 174-216; Idem, "La función misionera del poder civil según Juan Solórzano Pereira (1575-1655)", Studia Missionalia VI, (Roma: Facultate Missiologiae in Pont. Universitatis Gregoriana, 1951), pp. 106-125.

13 Paolo Broggio, "Teologia 'romana' e universalismo papale: la conquista del mondo (secoli XVI-XVII)", en M. Antonietta Visceglia (coord), Papato e politica internazionale nella prima età moderna, (Roma: Viella, 2013), pp. 441-477.
} 


\section{Los intentos de Rona para centralizar las misiones}

Ciertamente, el papado no podía permitir que los monarcas hispanos tomasen la doctrina católica como justificación política para su expansión territorial ni, lo que era mucho peor, justificar su existencia basándose en la teoría de la Monarchia Universalis, pues presuponía la subordinación jurisdiccional de la Iglesia a la de la Monarquía hispana. Por eso, tras concluir el concilio de Trento, se inició una dura pugna entre ambas organizaciones con vocación universal (la Iglesia y la Monarquía) para aplicar los acuerdos del concilio de acuerdo a los ideales de cada una de ellas ${ }^{14}$.

Sin duda ninguna, el proceso de soberanía e independencia que inició la Iglesia, también conllevaba inevitablemente la difusión de la doctrina católica por todo el mundo ${ }^{15}$; ahora bien, para este proceso se necesitaba, no solo ser los dueños de la doctrina, sino también disponer de personas, medios e instituciones a través de los cuales poder realizarlo. La Iglesia no tenía ejércitos para conquistar territorios y después implantar la religión sobre los vencidos como practicaba la Monarquía hispana, por lo que tuvo que basar su expansión en otros medios y valores: la predicación del Evangelio y el ejemplo personal de quienes la predicaban (misioneros); es decir, la expansión misional llevada a cabo por la Iglesia a partir de entonces ( $y$ hasta el día de hoy) fue pacífica. En este ideal, la Iglesia se pudo apoyar en las instituciones y órdenes religiosas, que practicaron una espiritualidad radical (como el movimiento de Felipe Neri, la Compañía de Jesús o los "descalzos" hispanos), nacidos durante el siglo XVI. Pero además, con el fin de articular y coordinar la expansión misionera (estableciendo normas, buscando recursos, asentando relaciones, etc.), Roma vio como algo indispensable crear una institución, la Congregación Propaganda Fide.

La primera idea de la fundación de este organismo parece remontarse a Pío V, si bien, fue Gregorio XIII, en 1572, quien nombró a tres cardenales para que entendiesen en los negocios de la fe. Y como no podía ser de otra manera, en estos primeros intentos, la labor que realizaron los carmelitas descalzos para expandir la religión al margen del sustento de la monarquía, resultaron fundamentales. El 19 de enero de 1582 quedaba concluida la fundación de los Carmelitas descalzos en la ciudad de Lisboa. El padre Gracián escribe que,

14 El proceso fue estudiado por José Martínez Millán (dir.), La Corte de Felipe II, (Madrid: Alianza, 1994), capítulo 40, "El inquisidor general Diego de Espinosa, en busca de la ortodoxia". 15 "Percio, il generale della Compania di Gesu, Francisco Borgia, proponeva a Pio V (15661572) di erigere una Congregazione di Cardinali per gli affari spirituali delle Missioni. L'iniziativa ando a vuoto per il fatto che Filippo II di Spagna non tollerava che i Cardinali si «immischiassero» negli affari missionari del suo impero. La stessa sorte tocco ad analoghe iniziative di Gregorio XIII (1572-1585) e Clemente VIII (1592-1605). Mancava aqueste Congregazioni anche una solida organizzazione e costituzione", en Josef Metzler, "La Congregazione «de Propaganda Fide» e lo sviluppo delle missioni cattoliche (ss. XVIII al XX)". Anuario Historia de la Iglesia, 9, (2000), p. 146; Klaus Jaitner, Die Hauptinstruktionen Gregors XV. Für die nuntien und gesandten an den Europâischen Fürstenhöfen 1621-1623, (Tübingen: Max Niemeyer Verlag, 1997), vol. I, pp. 56-59. 
de acuerdo con santa Teresa, ordenó al P. Nicolás Doria a Italia y a otros frailes a las Indias Occidentales y al Congo ${ }^{16}$.

En su Peregrinación de Anastasio, el padre Gracián narró las aventuras que tuvo que sufrir desde que salió de la orden carmelita (1592) hasta que fijó su residencia en Flandes (1607). En este libro ${ }^{17}$, Gracián deja claro el continuo trato que tuvo con los cardenales y con el papa Clemente VIII para que fundasen una Congregación de Propaganda Fide con su presidente o prefecto, siendo nombrado el cardenal de Santa Severina. El cardenal Bentivoglio, en sus famosas memorias, trazó la semblanza de este cardenal ${ }^{18}$. La primera vez que el cardenal de Santa Severina habló en su diario de la nueva congregación fue el 6 de mayo 159919: "Sobre el memorial de Su Santidad para la promoción de la religión católica en Oriente, a fin de fundar una congregación de cardenales, y se dé cuenta de todo a Su Santidad". La Congregación de cardenales se reunió por primera vez el 16 de agosto de 1599 y lo curioso es que no sabían cómo llamarle a dicha congregación. En la audiencia, el cardenal de Santa Severina la denomina Congregación de la Religión Cristiana. Después de la primera audiencia con el Papa se le denominó "Congregación de la Santa Fe y Religión Católica"20, posteriormente se modificó en "Congregación de la Santa Fe" hasta que el 6 de enero de 1600 aparecía con el título definitivo de "Congregación de Propaganda Fide"21. Parece que, aunque con vida lánguida, la congregación Propaganda Fide debió de existir hasta el año 1604, según lo da a entender el padre Juan de Jesús María22, cuando al dirigir a Clemente VIII su tratado sobre las misiones carmelitas dice que lo "ofrece con el fin de que sea examinado por la

\footnotetext{
16 Jerónimo Gracián, Estímulo de la propaganda de la Fe y vínculo y hermandad entre los padres descalzos del Carmen y san Francisco, (Lisboa: 1586, reimpreso en Bruselas 1609).; También, Jerónimo Gracián, Peregrinación de Anastasio, (Burgos: Monte Carmelo, 1905), pp. 50-51.

17 "Es que habiendo vuelto a Roma, después de cautivo, di muchos memoriales al Papa Clemente VIII, y uno de ellos anda impreso en un librito que se llama Redempción de cautivos, [Roma 1607 y Bruselas 1609], pidiendo a su Santidad se apiadase de tantas almas que padescían en aquellas partes [Berbería], por no tener ministros que les hiciesen fruto en la fe y costumbres. Fueron gran parte estos memoriales, y la solicitud continua con que hablaba a los cardenales de Roma sobre este caso, para que Su Santidad eligiese e instituyese una nueva Congregación de Cardenales, que se llama de Propaganda Fide" (Gracián, Peregrinación de Anastasio, p. 252).

18 "Pío V concedió la dignidad cardenalicia a Julio Antonio Sertorio, natural de Caserta, ciudad del reino de Nápoles, pero llámase de Santa Severina por el arzobispado de aquella ciudad, de la que ha sido arzobispo siendo ya cardenal. En las materias y cuestiones del Santo Oficio era reputado como un oráculo; y por aquella vía llegó a subir hasta el solio del pontífice Pío V, abusando mucho, a veces, de su celo santo. Así y todo, era verdaderamente grande eclesiástico, y a mi llegada a Roma se hablaba todavía mucho de aquel caso tan curioso, sucedido en el próximo pasado cónclave, en que el cardenal Santa Severina se vio en un punto Papa e non Papa, puesto que recayó después la elección unánime sobre el cardenal Aldobrandino", en Memorie del Cardinal Bentivoglio, (Milán: 1807), vol. IV, p. 368.

19 Archivio Segreto Vaticano (a partir de ahora ASV). Audientiae Card. S. Severinae cum Ssmo, I, anni 1595-1597; II, 1598-1602.

${ }^{20}$ Ibidem, fol. 98r.

21 Ibidem, fol. 122 r.

22 El venerable P. Juan de Jesús María, III General de la Congregación de Italia: su vida, sus virtudes y sus escritos, (Burgos: Monte Carmelo, 1919).
} 
Congregación de Propaganda Fide o por algún Prelado"23. El Pontífice, al saber por boca del Comisario General el voto del P. Juan, lo envió a "Persia", que era donde quería enviar a los misioneros carmelitas. Y desde aquel momento encargó a Pedro de la Madre de Dios la dirección de todas las misiones católicas, con lo que Clemente VIII puso fin a la primera Congregación Propaganda Fide24.

\section{La pugna entre Roma y la monarquía hispana por el control de la expansión de la religión}

Para culminar con éxito el proceso de soberanía y expansión, que el papado había iniciado ${ }^{25}$, resultaba imprescindible suprimir o, al menos, subordinar las facultades (emanadas de la Iglesia) que se arrogaba la Monarquía hispana, que le servían para justificar su actuación política. Dado que por la fuerza era imposible a causa del poderío militar de Felipe II, Roma buscó otros medios para conseguir su propósito. Como ya se estudió en otro trabajo ${ }^{26}$, si el papado favoreció la expansión de la espiritualidad "descalza" por los reinos hispanos y concretamente por Castilla, también consiguió formar un grupo o partido político (en torno al príncipe sucesor en el trono, Felipe III) en el que se atrajeron a cortesanos influyentes y, lo más importante, a miembros de la familia real.

Ya, en la embajada extraordinaria que realizó monseñor Camilo Borghese (octubre de 1593) a la corte hispana para solicitar ayuda contra los turcos, mientras pasaban los días esperando la audiencia del monarca, no se olvidó de visitar y cultivar la amistad del príncipe Felipe, de Isabel Clara Eugenia, del archiduque Alberto y de la emperatriz María, comunicando a Roma las buenas relaciones que existían entre estos miembros de la familia real y la devoción que profesaban a la sede apostólica ${ }^{27}$. A los pocos días de morir Felipe II, el 16 de septiembre 1598, el nuncio Caetani insistía en la misma

23 Juan de Jesús María, Historia Missionum Carmelitanum Discalceatorum, en Opera Omnia ejusdem, (Florencia: 1771-1774), vol. III, cap. III.

24 "Relación breve de la vida, virtudes y dichoso tránsito del Ven. P. Pedro de la Madre de Dios" (manuscrito de 45 folios en el Archivo de la Orden. Vita Ven. P. Petri a Matre Dei, cap. XV, en Opera Omnia Ioannis a J. M., vol. III, p. 616. Pedro de la Madre de Dios era natural de Daroca, donde nació en 1565. Profesó en Pastrana el 20 de enero de 1583. Fue enviado a Roma, asistió a morir al papa León XI y fue muy amigo del cardenal Baronio. Por cuatro años desempeñó el cargo de Superintendente General de las misiones. En Roma estableció una oficina desde la que mantuvo relación con los diversos misioneros. Después marchó hasta Japón. A su vuelta fue a tierras de herejes y a tierras de cristianos, como, por ejemplo, en la conversión de los moriscos que había aún en el reino de Valencia, mantuvo correspondencia con el obispo de Segorbe.

25 Paolo Prodi, El soberano pontífice, un cuerpo y dos almas: la Monarquía papal en la primera Edad Moderna, (Madrid: Akal, 2011).

26 Nos remitimos a la "Introducción" de Martínez Millán y Visceglia, La Monarquía de Felipe III, vol. I.

27 Ricardo de Hinojosa, Los despachos de la diplomacia pontificia en España, (Madrid: B.A. de la Fuente, 1896), pp. 367-368. 
apreciación ${ }^{28}$, al mismo tiempo que visitaba a la Emperatriz exhortándole a que interviniese ante el joven rey, su nieto, en favor de la Santa Sede ${ }^{29}$. Doña María siempre había constituido un potente foco de oposición al poder de los "castellanos" y un nexo seguro con Roma ${ }^{30}$, de lo que tenían clara conciencia sus propios servidores: así, don Juan de Borja, su mayordomo, buscaba el favor del cardenal Aldobrandini a través de Pedro Camerino, recordándole su cargo y a la persona a quien servía como garantía de ideología política ${ }^{31}$; pero también el grupo aragonés que le servía se mostraba anti-castellano: Lupercio Leonardo Argensola entró como secretario del duque de Villahermosa, don Fernando de Aragón, en 1586; siendo muy mozo asistió en Madrid a cierta academia poética ${ }^{32}$. El archiduque Alberto y su círculo de servidores también se encontraban dentro de la red clientelar de Roma: durante su estancia como gobernador de Flandes se estableció el primer nuncio permanente en dicho territorio ${ }^{33}$, mientras el grupo de servidores que había dejado en Toledo se mostraba fiel a Roma como testimonian sus numerosas cartas dirigidas al cardenal Pedro Aldobrandini ${ }^{34}$. Resulta lógico,

28 ASV, Spagna SS, lib. 49, fols. 289r-290r.

${ }^{29}$ Ibidem, lib. 49, fols. 307-311.

30 ASV, Spagna, tomo 327, fols. 17r-v. "Dalla copia del Breue che N. Sre., scriue alla Imper[atri]ce in risposta di quello che S. Mta. pregó V.S a far sapere a S. Sra., nel particolare dell'Imperatore et de gli'altri sere[nisi]mi suoi figliuoli, hauerà V.S. campo molto largo et aperto per rendere secura la Mta., sua dell'amor paterno che sua Beat[itudi]ne porta et all'Imperatore et alli sermi., suoi figliuoli verso quali sà tutto il mondo quante sieno state le segnalate dimostrationi fatte da S.Sta., in tutte le occorrenze loro, nelle quali non ceserrá S. Bne., di mostrare alla medesima imperatrice la contineratione del suo affetto, di che V.S. può render cosi sicura S.Mta., che per alcun tempo non hauerá occasione di desiderarlo maggiore. Vorrebbe bene la sta., sua che questo amore non solo fosse conosciuto, ma riconosciuto con la esecutione de suoi buoni, et santi ricordi, et in particolare di quelli che toccano la salute dell'anime, il beneficio delle chiese, et il culto et seruitio di Dio nelle stati di sua Mta., che all'ultimo questi non tendono ad altro fine, che alla grandezza della medisima Mta., et della serma., casa sua, et perche dalla sudta., copia di breue et dai particolari che si contengono in esso, V.S. potrá discorrere pienamente sopra i partic[ola]re che desidera I'Imperatrice, non mi estendero in altro ma col fine prego Dio le conceda ogni vero bene. Di Roma a di 9 di Genn[ai]o $1599 "$.

31 "Il sr. Giovanni de Borgia, maggiordomo de la Maestà dell'Imperatrice et del Real Consejo di S. Mta et in oltre streccisimo parente del sr. Marcesse de Denia, sapendo che io son tenuto da V. S. I per uno de suoi minimi servi mi ha comandato che io le incamini questa lettera de S. Mta dell'Imperatrice si come faccio con la presente certificándole che el do sr. Don Giovanni Borgia é uno delli compiti cavalleri che que tenga questa corte, signore assoluto della casa dell'Imperatrice et di molta authorit', non solo con sua Maestà dell' Imperatrice ma anco con la Maestà del Re et si precia grandemente di essere molto devoto et partial servidor di V. S.i et certo che per diverse cause sel' ha de mantener in questa devotione di volontà con favorer la cose sue presso la la Sta di No Sa circa la pretensión di un suo figlio prete" (Ibidem, lib. 52, fol. 301r).

32 Es muy posible que fuera la de los Humildes, cf. José Sánchez, Academias literarias del siglo de oro español, (Madrid: Gredos, 1961), pp. 34-35.

33 Leon van der Essen, Correspondence d'Ottavio Mirto Frangipani. Premier nonce de Flande (1596-1606), (Roma-Paris-Bruxelles: 1924).

34 "Eme de valer de la merced que V. S. I, me hace en todas las ocasiones que se me ofrecieren, mayormente las que tocaren al señor cardenal Archiduque. Su alteza dexó aquí a Juan Carrillo, tesorero y canónigo de Ávila, por su secretario, que asiste conmigo, y es también su contador mayor de la hacienda, persona de quien su alteza echó mano por ser muy importante y de mucha inteligencia para su servicio". Carta de Loaysa al cardenal Pedro Aldobrandini, fechada el 8 de diciembre de 1598, añadiendo de su puño: "Toda la merced que V. S. I, hiciere a Juan Carrillo lo será para mí y cosa muy acepta al cardenal archiduque porque aquí lleva todo el peso de toda la gobernación deste Arzobispado" (ASV, Spagna, S.S., lib. 51, fol. 478r). Asimismo, (ASV, lib. 52, fol. 134r). 
por tanto, el triunfalismo que mostraba el nuncio Caetani el mismo día que moría el Rey Prudente en carta dirigida al cardenal Aldobrandini:

"La comune opinione che corre per la corte e che dovendo S. Sta inviar legato como par che richiedano li occni. di condoglienza per la morte di S. Matà et di congratulationes por gli casamenti del nuovo Re et de la serenísima infanta, fara indubitablemente ellectione della persona di V. S. I. Il che succedendo come spero, son per sentir tanto gubilo et allegria che non capiro in me stesso con per veder? aggiunto quest'honore a tanti altri reporti nella grandeza dell' Illma persona sua come per promettermi dalla somma benignita di V. S. Illma sicura l'effettuatione della gratia che si degno farmi di questa secretariado della collectoria a contemplatione dell'Illmo cardenal Borghese"

Esta captación de personajes cortesanos influyentes por parte del papado, fue acompañada de una intensa actividad ideológica sobre la fundamentación y justificación de la Monarquía, expresada en numerosos tratados y escritos (elaborados en su gran mayoría por frailes descalzos) en los que se defendía la subordinación de ésta a la jurisdicción de la Iglesia (Monarquía Católica) ${ }^{36}$. Ahora bien, una cosa era la asunción de la ideología religiosa, por parte de la sociedad hispana, que predicaba la Iglesia y otra muy distinta era aceptar la renuncia a los privilegios de conquista, que poseían los monarcas hispanos, en aras de una Congregación que iba a crear la Iglesia para asumir estas actividades. El papado tuvo que actuar con mucho cuidado para conseguir su objetivo: en primer lugar, crear la necesidad de fundar esta institución (Congregación Propaganda Fide) a través de la creciente actividad misionera (por todo el mundo) de las órdenes religiosas implicadas en el asunto; en segundo lugar, atraer a miembros relevantes de la familia real hispana que, no solo estuvieran de acuerdo con la religiosidad y espiritualidad de Roma, sino que además ayudasen a crear las infraestructuras (donaciones económicas, apoyo político, etc.) de este proyecto eclesiástico, que (aunque disimuladamente) iba a recoger las facultades que tenía la Monarquía hispana para ejercer su expansión que en tiempos anteriores le habían otorgado los pontífices.

\section{a) La creciente actividad misionera de las órdenes religiosas}

Bajo el pontificado de Paulo V (1605-1621), la evangelización cobró un nuevo impulso. Ordenó que a los territorios del rey español no solo fuesen

35 ASV, lib. 52, fol. 145r. Fechada en Madrid, a 13 de septiembre de 1598.

36 Desde el punto de vista práctico, los "recursos de fuerza" resultaron, sin duda, el conflicto más acuciante, por lo que Roma intentó por todos los medios que la Monarquía renunciase a ellos. Véase el estudio preliminar de Luciano Pereña de la obra de Juan Roa Dávila, De regnorum iustitia, (Madrid: CSIC, 1970), pp. XV-LIV. 
religiosos hispanos, sino también italianos ${ }^{37}$, si bien el papa puso el acento más en la diplomacia que en las misiones. Además de los misioneros franciscanos y dominicos de la Edad Media, la renovación del catolicismo fue realizada por nuevas órdenes religiosas: capuchinos, jesuitas, Carmen descalzo. El Carmen descalzo español ya hizo una gran expansión misional en Hungría, el Congo, etc., bajo el impulso de tres grandes misioneros: Jerónimo Gracián, Domingo de Jesús María y Tomás de Jesús ${ }^{38}$. Los superintendentes del papa en misiones (antes de la creación de la Congregación Propaganda Fide) por el mundo partieron de esta Orden ${ }^{39}$. Clemente VIII envió a Pedro de la Madre de Dios a este puesto y después de su muerte, en 1608, Paulo V nombró a Domingo de Jesús María (1559-1630). La actividad del futuro general de los carmelitas, Domingo de Jesús María, estuvo estrechamente ligada a la historia de la renovación del catolicismo en Europa central, después, en 1620, él sostuvo la moral de las tropas católicas en la batalla de Montaña Blanca y participó en el consejo de guerra antes de la batalla ${ }^{40}$.

Otro carmelita, el padre Tomás de Jesús (1564-1627), que se formó en la misión al Congo, escribió -en 1613- un tratado titulado De procuranda Salute Omnium Gentium a propósito de la obligación de crear un centro independiente en Roma para todas las misiones a través del mundo, evidentemente bajo la dirección de su orden, los carmelitas descalzos. Tomás de Jesús descendía de la familia de los Sánchez-Dávila. Nació en Baeza en 1564, en cuya universidad comenzó a estudiar, pasando más tarde a la de Salamanca, donde se doctoró en teología. Profesó en Valladolid el 5 abril 1587. Después fue lector de teología en los colegios de Alcalá y Sevilla; prior por dos veces del convento de Zaragoza; prior del desierto de las Batuecas, provincial de Castilla, definidor general de la congregación de España y, poco después, de Italia ${ }^{41}$.

El Padre Tomás partió para Roma (llamado por el pontífice) sin manifestar a nadie de lo que iba a tratar, por lo que los Superiores de la Congregación de España lo denunciaron ante el monarca y ante el papa. Cuando el embajador español en Roma se dispuso a quejarse ante el pontífice, éste le dijo que lo había llamado él, lo que deja claro que las cuestiones misionales

37 Silvano Giordano, Le istrutioni generali di Polo $V$ ai diplomatici pontifici, 1605-1621, (Tübingen: Max Niemeyer Verlag, 2003), vol. I, p. 93.

38 Florencia del Niño Jesús, La Orden de Santa Teresa, la fundación de la Propaganda Fide y las Misiones Carmelitanas, (Madrid: Tip. Nieto, 1923), pp. 21-32; Tarsicio del Santísimo Sacramento, "Los Carmelitas Descalzos y la Sagrada Congregación de Propaganda Fide", El monte Carmelo, 60 (1952), pp. 37-68.

39 Jesús María, Historia Missionum Carmelitanum Discalceatorum, vol. III, cap. VIII; Giovanni Pizzorusso, "Il papato e le missioni extraeuropee nell'epoca di Paolo V. Una prospettiva di sintesi", en Alexander Koller (ed.), Die Außenbeziehungen des Römischen Kurie unter Paul $V$. Borghese (1605-1621), (Tübingen: Max Niemeyer Vlg., 2008), pp. 367-390.

${ }^{40}$ Olivier Chaline, "La bataille de la Montagne Blanche (8 novembre 1620). Un mystique chez les guerriers, (Paris: Editions Noesis, 1999), pp. 231-251.

${ }^{41}$ Su biografía en: Francisco de Santa María, Reforma de los Descalços de Nuestra Señora del Carmen de la primitiva Observancia, (Madrid: por Diego Diaz de la Carrera, 1644), IV, lib. XVII, caps. 36-42. 
se desarrollaban en secreto. De hecho, el 31 de julio de 1607, el rey escribía a su embajador en Roma para que propusiera al papa enviar religiosos dominicos a las misiones del Congo, poniendo veto a los carmelitas de los que desconfiaba.

Finalmente, los trabajos misionales abiertos en las diferentes partes del mundo fueron reunidos en esta Congregación, que se compuso en su origen de trece cardenales (su número aumentó enseguida). El prefecto de la Congregación fue siempre un cardenal de gran autoridad, pero el trabajo, en el sentido estricto, lo efectuó el secretario. El peso de esta institución en el seno de la curia romana se demuestra en el hecho de que sus miembros fueron escogidos entre los cardenales más influyentes. En noviembre de 1622, Gregorio XV nombró para regir la Congregación a su primo el cardenal Ludovico Ludovisi, que la dirigió hasta 1632, fecha en que el papa Urbano VIII (1623-1644) le destituyó. En el transcurso de las tres décadas siguientes (1622-1649), el secretario Ingoli fue uno de los actores principales de Congregación ${ }^{42}$. El dicasterio de Propaganda Fide comenzó a seleccionar misioneros, dóciles a las instrucciones de la Congregación, prontos en comunicar a Roma noticias y su apostolado, ajenos a la autoridad secular del Patronato (en definitiva, "descalzos"). La Congregación buscaba una reforma de los conventos infundiéndoles el espíritu misionero y suplantando su vida contemplativa por otra más activa ${ }^{43}$.

Pero, además, el papado vio la necesidad de crear un centro de educación de acuerdo al nuevo espíritu como fue el Colegio Urbano en Roma. El Colegio Urbano, convertido en Universidad de la Propaganda Fide, fue fundado en 1627 por Urbano VIII en la bula Inmortalis Dei Filius, 1 de agosto de $1627^{44}$. El 1 de junio de 1626, con la aprobación del pontífice, Juan Bautista Vives concedía una renta anual de 715 escudos con los que fundaba la ayuda económica para 12 alumnos, que bajaron a 10 porque las rentas no bastaban. El 1 de abril de 1637, el mismo papa concedía una renta de 843 escudos para ayuda económica de doce alumnos que ponía su hermano, el cardenal Antonio Barberini. El 21 de junio de 1639 confirmó otra fundación del cardenal de 857 escudos para 13 jóvenes. Para esta fecha, en total, había 35 plazas que intentaban educar para la vida misionera en el Colegio Urbano. A partir de aquí se fueron creando otros colegios con el mismo espíritu ${ }^{45}$.

\footnotetext{
42 Josef Metzler, "Francesco Ingoli, der erste Secretar der Kongregation (1578-1649)", en Josef Metzler (dir.), Sacrae Congregationis de Propaganda Fide. Memoria rerum, (Roma: 1972), vol. I/1, pp. 197-243.

43 Massimo Marcocchi, Colonialismo, cristianesimo e culture extraeuropee. La istruzione di Propaganda Fide ai vicari apostolici dell'Asia orientale (1659), (Milán: Jaca Book, 1981).

${ }^{44}$ Bullarium Pontificium S. C. de Propaganda Fide (Romae: 1839), vol. I, pp. 69-72. Giuseppe Piras, La congregazione eil collegio di propaganda fide di J. B. Vives, G. Leonardi e M. De funes, (Roma: Università Gregoriana, 1976), pp. 11-15; Nikolaus Kowalsky, Pontificio Collegio Urbano de Propaganda Fide, (Tivoli: Tip. A. Chicca, 1956).

45 Saverio M. Paventi, "Congregazione Urbaniana super facultatibus missionariorum", Studia missionalia, 7, (1952), pp. 217-240.; Idem, "Origo Congregationis Urbanianae super facultates missionariorum", Commentarium pro Religiosis et Missionariis, 24, (1943), pp. 288-300 y 25, (1944), pp. 73-86.
} 
Paulatinamente, la Congregación fue extendiendo decretos y promulgando instrucciones para su funcionamiento, que los enviaban a los capítulos generales celebrados por las distintas órdenes. No obstante, en 1659, la Congregación extendió una larga Instrucción que, en buena medida, venía a resumir o incorporar todos los decretos promulgados hasta entonces, por lo que puede considerarse como el punto de partida programático de la Congregación. Durante mucho tiempo, esta Instrucción vino a ser como el "manual" para las misiones de la Propaganda46. El punto esencial de este "manual" fue que la Congregación consideraba como su obligación principal separar las actividades misioneras de la actividad política de los Estados. Ello significaba liberarse en su actuación del patronato real de las grandes potencias coloniales, España y Portugal ${ }^{47}$. En una instrucción general, enviada a los misioneros, se les decía que los misioneros de la Congregación nunca debían perder de vista que eran enviados para convertir a los pueblos a la religión católica ${ }^{48}$. De acuerdo con este ideal, la Congregación vio como necesario adoptar un "método misionero", lo que se tradujo en un interés especial por la pastoral. A partir de entonces, la Congregación ordenó a los nuncios, y superiores de las órdenes religiosas que para la conversión de infieles no se utilizaran "procedimientos violentos o extraordinarios", sino que se empleasen "métodos dulces y cariñosos que ellos son los del Espíritu Santo" 49 .

\section{b) La Congregación Propaganda Fide y la Monarquía Católica: la corte de los archiduques en Bruselas}

Pero como resulta fácil de deducir, el problema mayor de la Congregación estuvo en conseguir el consentimiento de la Monarquía hispana para que dicha institución centralizase la expansión del cristianismo por el mundo. El

\footnotetext{
46 Collectanea S. Congregationis de Propaganda fidei seu Decreta, Instructiones, Rescripta pro Apostolicis Missionibus ex Tabulario e eiusdem Sacrae Congregationis deprompta, (Roma: 1893), vol. I, pp. 185-210.

47 Carl Piepper, Die Propaganda. Ihre Entstehung und religiöse Bedeutung, (Aachen, Immensee: Xaveriusverlagsbuchh, 1922), p. 32.

48 "L'altro mezzo, e soccorso, che solo vi resta è la via della pietà, ed'institutione cristiana per mezzo d'huomini dotto di predicatori, e de buoni virtuosi sacerdoti, i quali pigliano cura di conservare i cattolici, e mostrare à gli eretici i loro errori, ne' quali à persuasione di huomini sceleratissimi sono incorsi e vivono [...] E questa maniera, e propria della legge cristiana osservata da nostri maggiori e da santi Padri per fino al tempo degli Apostoli, e dagli Apostoli sin hora. Di che habbiamo bellissimo essempio da Gregorio VII [...] E questo è antico stile della chiesa Romana, come si vede nel fatto di San Gregorio Papa, il quale mandò in Inghilterra alcuni santi religiosi dell'ordine di San Benedetto che diedero principio alla conversione di quel Regno, e Gregorio II, che mandò in Germania San Bonifatio Arcivescovo poi di Magonza, che ridusse, o converti gli Alemanni alla Santa Fede. Hor quel che fecero gli antichi pontefici, perche non lo continueranno i moderni, poiche l'obbligo è l'istesso, e forsi maggiore?", (Archivio Storico di Propaganda Fide (ASPF), SOCG, 362, I Collegi, f. 13r.); Henri Chapoulie, Aux origines d'une église. Rome et les Missions d'Indochine au XVIIe siècle, (París: Bloud \& Gay, 1943), vol. I, pp. 392-402.

49 En una respuesta a una pregunta que un misionero envió desde la India, se le recordaba que "nosotros predicamos a Cristo Crucificado" (I Cor. 1, 23). ASPF, Collectanea S. Congregationis, I, 25.
} 
proceso fue complicado y se dio, prácticamente, a lo largo de todo el siglo XVII, donde se dieron toda clase de conflictos jurisdiccionales. A nuestro juicio, la primera victoria de Roma en este asunto se dio, precisamente, en Flandes, y tuvo como protagonistas a la infanta Isabel Clara Eugenia (gobernadora de aquellos territorios) y también, aunque en menor influjo a su esposo el archiduque Alberto. Este apoyo fue continuado por otro miembro de la familia real, el cardenal infante don Fernando.

La infanta Isabel Clara Eugenia puede ser considerada como una genuina "infanta castellana". Había nacido el 12 de agosto de 1566, justamente cuando su padre, Felipe II, iniciaba el proceso de confesionalización de su Monarquía. Como ya hemos estudiado en otros trabajos, este proceso consistió no solo en la organización institucional de la nueva Monarquía (la que había heredado Felipe II), sino también en la imposición del catolicismo de acuerdo con los ideales, intereses y espiritualidad castellanos. La infanta Isabel Clara Eugenia asumió estos valores e ideales desde su niñez y adolescencia, en los que vivió este proceso y fue testigo de la reorganización de la Inquisición, de la catequización de los moriscos, de la imposición de los acuerdos de Trento según la conveniencia de la Monarquía, reforma de las órdenes religiosas de acuerdo a los criterios de Felipe II, imponiéndoles una espiritualidad ascética e "intelectual", basada en la manifestación externa de las vivencias y creencias religiosas de la persona ${ }^{50}$. Desde el punto de vista político, la Infanta vivió la organización institucional de la Monarquía, efectuada por los letrados, y sobre todo la conquista de Portugal, máximo triunfo político del "partido castellano". Es decir, fue una obediente hija de Felipe II (como los historiadores vienen repitiendo hasta la saciedad) tanto en su conducta filial como en la identificación ideológica y espiritual.

Con todo, la insatisfacción espiritual que produjo esta práctica religiosa formalista y reglamentada (alentada por la misma tendencia espiritual que defendía Roma) en determinados sectores sociales, motivó que surgieran reacciones más radicales y vivenciales que tendieron a la mística, si bien, para poder ejercerlas había que guardar las formalidades religiosas que seguía el movimiento religioso defendido por la Monarquía; este fue el caso del Carmelo de santa Teresa y del movimiento "descalzo" en general ${ }^{51}$. Santa Teresa se percató de que para implantar la reforma religiosa que pretendía realizar en su Orden, era preciso tener el beneplácito y la confianza del rey y de asumir una religiosidad externa de acuerdo con la ortodoxia castellana. Es preciso señalar que toda su obra la realizó durante la etapa del confesionalismo filipino; es decir, durante la niñez y adolescencia de Isabel

\footnotetext{
50 Emilio Colunga, "Intelectualistas y místicos en la teología española del siglo XVI", Ciencia Tomista, 10, (1915), p. 232, afirma: "La generalidad de los Dominicos seguía la tendencia intelectualista".

51 José Martínez Millán, "La reforma espiritual de Santa Teresa de Jesús y sus relaciones con las facciones cortesanas", Hispania Sacra 67, (2015), pp. 429-466 (on-line https://repositorio.uam.es/bitstream/handle/10486/671039/reforma_martinez_hispsa_2015. pdf?sequence $=1$ ).
} 
Clara Eugenia. La propia Santa recibió la ayuda de la Infanta en la etapa final de su vida, cuando las dificultades para fundar eran más fuertes por la oposición de su propia Orden.

Una serie de circunstancias vinieron a influir en el ánimo de la Infanta de manera que paulatinamente se fue alejando de la religiosidad de su padre a la vez que se decantaba por la espiritualidad radical y vivencial. Sin duda ninguna, la influencia más inmediata procedía de la espiritualidad del convento de las Descalzas Reales, donde se hallaba su tía, la emperatriz María, desde 1580, a la que visitaba con frecuencia. En este monasterio, fundado por doña Juana de Austria, hermana de Felipe II, siempre se practicó una religiosidad recogida, contraria a la seguida por la facción cortesana castellana y guardó un halo de "oposición" al gobierno "castellano" del Rey Prudente, debido a la protección y refugio que siempre ofreció a los personajes marginados del poder, tales como los aragoneses fieles a la emperatriz María o el grupo de resignados que integró el servicio de la infanta Catalina Micaela en su viaje a Saboya52. Todos ellos adoptaron, como forma de vida y práctica espiritual, la religiosidad dirigida directamente por el papado (relegado también en el campo político como ellos), formando así una ideología (política y religiosa) opuesta a la que venía ejerciendo el grupo castellano.

No fue menor el influjo que ejercieron los nuncios apostólicos, bien directamente o a través de personas interpuestas. Desde los tiempos de Gregorio XIII (1572), todos los pontífices intentaron formar un grupo o "partido" en la corte de Felipe II que compartiesen las ideas religiosas de Roma y que influyeran en gobierno para recuperar la jurisdicción eclesiástica que se arrogaba el monarca hispano. La labor no resultó infructuosa y se hizo evidente a partir del matrimonio y posterior viaje de la infanta Catalina Micaela a Saboya (1585) con el Duque de Saboya, cuya casa estaba llena de esta gente desplazada del poder central de la Monarquía y muy afines a la ideología que defendía Roma. El 20 de marzo de 1585, mientras todavía se celebraban las fiestas por la boda de Carlos y Catalina en Zaragoza, se hicieron públicos los nombramientos de los principales oficios de la casa que debía instalarse con la infanta en la corte de Saboya: el milanés, barón Paolo Sfondrato, embajador de Felipe II en Turín, fue nombrado mayordomo mayor. El marqués Carlo Pallavicino, embajador del duque de Saboya en la

\footnotetext{
52 Sobre el círculo aragonés y la protección que ejerció doña María, Instituto Valencia de Don Juan (IVDJ), env. 101, fols. 128r, 138r, 139r.; Otis Howard Green, Vida y obras de Lupercio Leonardo de Argensola, (Zaragoza: Institución Fernando el Católico, 1945), pp. 30-49.; También, José Martínez Millán, "La emperatriz María y las pugnas cortesanas en tiempos de Felipe II", en Ernest Belenguer Cebriá, Felipe II y el Mediterráneo, (Madrid: 1999), III, pp. 143-163.; Elías Tormo, En las Descalzas Reales de Madrid. Estudios históricos, iconográficos y artísticos, (Madrid: Sociedad Estatal para la Conmemoración de los Centenarios de Felipe II y Carlos V, 1917), pp. 153-177; se hace eco de esta oposición de las Descalzas. La lista de servidores de Catalina Micaela que llevó a Saboya, en: Archivo General de Simancas (AGS), Consejo Real, leg. 613, y la lista de los que volvieron a Castilla tras su muerte, en AGS, CJH, leg. 473, carp. 13.
} 
corte de Madrid, fue nombrado caballerizo mayor. Doña Sancha de Guzmán fue su camarera mayor; era hija de Hernando Álvarez de Toledo y de doña Juana de Acuña y viuda de don Luis Méndez Portocarrero ${ }^{53}$. Además, se formalizó el número de servidores que debía llevar, dos dueñas de honor, tres damas, una dueña de retrete, que haría las funciones de guardamanger, cuatro mozas de cámara, tres mozas de retrete, una guarda de damas, un guardajoyas con funciones en la guardarropa y en la tapicería y un repostero de camas $^{54}$. Los nombres -según la relación de don Juan de Zúñiga55_ eran, como dueñas de honor, doña Antonia de Mendoza y doña Mariana de Tassis; damas, doña Luisa Manrique y doña Ana de Mendoza, hija de Antonia; la dueña de retrete era la antigua azafata de la infanta, Doña Luisa Mexía y Sandoval, a la que acompañaba su sobrino como repostero de damas. El guardajoyas fue Luis Gutiérrez, mientras que sus dos hijas se nombraron mozas de cámaras; dos mozas de retrete eran hijas del portero de la casa del Pardo. Acacio de Loaisa fue nombrado guarda de damas ${ }^{56}$.

Con todo, es preciso señalar que durante la última década del siglo XVI, el papado consiguió formar una red cortesana de personajes influyentes en torno al príncipe heredero (el futuro Felipe III) y de la propia Isabel Clara Eugenia ${ }^{57}$, cuyos miembros defendían fielmente los intereses de Roma. Entre los nobles captados para la causa romana, es preciso destacar al conde de Puñonrostro, quien no ocultaba la amistad y fidelidad que le unía a la familia Aldobrandini, manifestando abiertamente su papel de broker que reunía a partidarios de Roma en los reinos hispanos ${ }^{58}$. Lo mismo que su esposa, quien

53 Doña Sancha era hija de Hernando Álvarez de Toledo y de doña Juana de Acuña y emparentada, por línea materna, con el conde de Buendía, camarero mayor del rey. Véase, José Martínez Millán y Santiago Fernández Conti (dirs.), La Monarquía de Felipe II. La Casa del Rey, (Madrid: Mapfre, 2005), vol. II, pp. 18-19.

54 Archivo Zabálburu (AZ), carpeta, 85, núm. 29.

55 Franco Varallo, De Nizza a Torino. I festeggiamenti per il matrimonio di Carlo Emanuele I e Catalina d'Austria, (Turín: Centro Studi Piemontesi, 1992); María José del Río Barredo, "De Madrid a Turín: el ceremonial de las reinas españolas en la corte ducal de Catalina Micaela de Saboya", Cuadernos de Historia Moderna, 97, (2003), Anejo II, pp. 97-122.

56 AGS, E, leg. 1260, núm. 199. Fechada en San Lorenzo, a 3 de enero de 1585 . Blythe Alice Raviola, "La imagen de la infanta Catalina Micaela en la correspondencia de los gobernadores piamonteses", en Las Relaciones Discretas ente las Monarquías Hispana y Portuguesa. Las Casas de las Reinas coord. José Martínez Millán y Maria Paula Marçal Lourenço, (Madrid: Polifemo, 2008), vol. III, pp. 1738-1741, señala los servidores saboyanos que le ayudaban a escribir las cartas y en los asuntos de gobierno. Pero, el mejor estudio sobre la educación y casa de la Infanta es, sin duda, el dirigido por Blythe Alice Raviola y Franca Varallo, L'Infanta Caterina d'Austria, duchessa di Savoia (1567-1597), (Roma: Carocci Editore, 2013).

57 Santiago Martínez Hernández, "Reyna esclarecida, Cynthia clara, hermosa luna: el aprendizaje político y cortesano de la infanta Isabel Clara Eugenia", en Isabel Clara Eugenia. Soberanía femenina en las cortes de Madrid y Bruselas, coord. Cordula Van Wyhe, (Madrid: CEEH, 2011), pp. 45-47.

58 Así, el uno de junio de 1594 recomendaba a Juan Orozco Covarrubias y Leiva, sobrino del gran prelado Covarrubias, presidente del Consejo de Castilla, que "va proveído por obispo de Girgento en Sicilia, plaza muy desigual por sus muchos méritos, pero principio para que éstos y el favor de V. S. I, le suban donde merece", y al doctor don Pedro Arias Dávila y Virues, "mi primo", que poseía iguales méritos, para que le concediera una canonjía de Segovia. En ASV, Spagna, S. S., lib. 51 , fols. 178 r y 180 r y 415 r. 
manifestaba al pontífice la influencia que su familia tenía en la Orden de San Agustín para serle fiel ${ }^{59}$.

Otra de las familias vinculadas a Roma eran los Cardona, como testimonia doña Margarita Cardona al cardenal Aldobrandini: "Hallándose ya en esa corte don Francisco de Diechtristein, mi hijo, y siendo tan servidor de V. S. I, como criado de Su Santidad, quedo yo contentísima y con mucha esperanza de que en las ocasiones que tocasen al acrecentamiento de su persona hará V. S. I, siempre tanta merced como me dicen que le hizo en la vacante del obispado de Olmuz [sic] y despacho e los breves que en su tenor se escribieron al emperador y al cabildo"60. La fidelidad de los Cardona fue premiada pocos años después, elevando a su hijo a cardenal61. El 21 de agosto de 1599, el propio marqués de Cardona daba las gracias al cardenal Aldobrandini por haber elegido a su hijo, el cardenal Diechtristein, legado cerca del archiduque Alberto $^{62}$. El duque de Sessa era otro noble considerado papista socialmente, como testimonia el virrey de Cerdeña al propio pontífice ${ }^{63}$. El propio Sessa declaraba personalmente la fidelidad a la familia Aldobrandini, confirmando lo que era opinión común tanto en la corte romana como de Madrid. Por su parte García de Loaysa manifestaba su dependencia del cardenal Aldobrandini de esta manera tan llana: "siempre que se ofrece en que V. S. I, me haga merced, lo suplico de muy buena gana por la confianza con que quedo en recibirla como hasta aquí"64. Ya, en enero de 1596, enviaba una relación detallada del modo cómo había sido recibido Juan Francisco Aldobrandini en la corte de Felipe II, sin omitir tampoco las atenciones que él mismo le obsequiaba65. No resulta extraño que, el 10 de mayo de 1598, le escribiera: "Su Majestad se a servido nombrarme a Su Santidad para el arzobispado de la Santa Iglesia de Toledo ... Suplico a V. S. I, me ampare y favorezca significando a Su Santidad esta voluntad de hechura suya muy reconocida. $Y$ por esta obligación y otras muchas en que me conozco a V. S. I, le he de servir siempre con el respeto y puntualidad que es razón"66. La dependencia de Loaysa a Roma se manifestaba en las numerosas peticiones de favores que hizo el prelado: para sus sobrinos Fernando Girón y Álvaro de Carvajal, al general de la Orden de Santo Domingo, etc ${ }^{67}$. García de Loaysa fue nombrado gobernador del arzobispado de Toledo en 1595 a causa de la ausencia del archiduque Alberto, nombrado gobernador de Flandes. Fue preceptor del príncipe Felipe (III), reorganizador del Consejo de la

\footnotetext{
59 Ibidem, fol. 8r, carta fechada a 3 de septiembre de 1592. "Con fray Pedro de Perea escribí a Vuestra Santidad a 10 de agosto, y aviendose ofrecido ocasión de ir fray Pedro Manrique, mi hermano, a esa ciudad por haberle nombrado en el capítulo de la Orden de San Agustín, que profesa, por asistente general de ella, he tenido por grandísima ventura que aya de residir ahí, donde pueda acudir ordinariamente al servicio de Su Santidad".

60 ASV, Spagna. S. S., lib. 52, fol. 118r. Madrid, a 29 de Julio de 1598.

61 Ibidem, lib. 52, fol. 81r. Madrid, a 24 de mayo de 1598.

62 Ibidem, lib. 52, fol. 481r.

63 Ibidem, lib. 51, fol. 23r. Caller, a 5 de febrero de 1593.

64 Ibidem, lib. 51, fol. 185r.

65 Ibidem, lib. 51, fol. 478 r.

66 Ibidem, lib. 52, fol. 42r.

67 Ibidem, lib. 51, fol. 299r; lib. 52, fol. 16r, 115 r.
} 
Gobernación del arzobispado68, visitador general y gobernador del arzobispado de Toledo. El marqués de Velada también se arrimó a la protección de Roma, así lo escribía el 5 de mayo de 1598: "El deseo que tengo de servir a Vuestra Santidad merece muy bien la merced que Vuestra Santidad me ha hecho con el breve de 26 de noviembre pasado, que me dio el nuncio Paulo Emilio Zachia y en lo que traía a su cargo, e procurado servir a Vuestra Santidad como lo he de hacer en todo y el más particularmente dirá, a quien he pedido suplique a Vuestra Santidad de mi parte me mande siempre en qué servir a Vuestra Santidad como quien tanto lo desea hacer"69. Por su parte, el marqués de Poza escribía al cardenal Aldobrandini su deseo de servirle "tengole tan grande de cumplir esta obligación que si supiere que ay alguna que fuese del de V. S. I, no aguardaría que me lo mandase"70. El 20 de septiembre de 1599, el marqués de Poza escribía a Aldobrandini solicitando una merced para su sobrino Pedro de Guzmán ${ }^{71}$. No lo fue menos el conde de Miranda, como comunicaba el propio nuncio Caetani al cardenal Aldobrandini, "Del conde de Miranda tenemos necesidad en todo y a todas horas, se muestra muy parcial servidor de Su Santidad y el ministro más afecto de todos a las cosas de la Iglesia"72.

\section{c) La corte de Isabel Clara Eugenia en Bruselas}

El hecho de que Alberto e Isabel fueran nombrados gobernadores de los Países Bajos resultó muy importante, dada la dependencia de estos territorios a la Monarquía hispana y fidelidad de las facciones cortesanas que dominaban la corte de los territorios del sur con el gobierno de Madrid. No resulta pertinente estudiar la política que el matrimonio siguió en Flandes (por otra parte, ampliamente investigada), sino que nos interesa destacar la ideología política y la espiritualidad que practicó la Infanta (que compartía con su esposo) para entender nuestro proyecto.

Como se ha señalado, la reforma de Teresa de Jesús no podía ser admitida por el gobierno de los letrados castellanos ya que en su origen llevaba "el sello de la independencia eclesiástica de toda injerencia civil"73, por lo que la Santa se dio cuenta de la persecución política a la que se podía ver sometida su obra, como en realidad sucedió, y el enfrentamiento político entre la corte de Madrid y la de Roma que podría ocasionar ${ }^{74}$. La obra de Teresa de Jesús

\footnotetext{
68 Manuel Gutiérrez García-Brazales, "El Consejo de la Gobernación del Arzobispado de Toledo", Anales Toledanos 16 (1983), pp. 63-138.

69 ASV, Spagna, lib. 52, fol. 70r.

70 Ibidem, lib. 52, fol. 91r. Madrid, a 2 de junio de 1598.

71 Ibidem, lib.52, fol. 503r.

72 ASV, lib. 52, fol. 68r, carta del conde de Miranda al cardenal Aldobrandini, fechada en Madrid, a 19 de mayo 1598.

73 Carmelo de la Cruz, "La reforma teresiana instrumento de la reforma de Trento", El Monte Carmelo, 74, (1966), p. 313.

74 Otger Steggink, "Observancia y Descalcez carmelitana: reforma romano-tridentina y «reforma» (española) del Rey: un conflicto y su primera víctima", en San Juan de la Cruz,
} 
fue continuada por el padre Gracián de la Madre de Dios, por eso, cuando en 1582, murió la Santa, la estrella del padre Gracián comenzó a descender; tuvo que dejar el cargo de provincial siendo nombrado en su lugar Nicolás de Jesús Doria, defensor de la observancia regular y legalista muy en consonancia con el espíritu "castellano". Gracián fue enviado a Portugal, donde publicó su Estímulo de la propagación de la fe (1586), que no fue bien recibido por el nuevo provincial y sus partidarios. En aquellos días predicó en Lisboa con "crédito de la Orden y afición de los Portugueses"75 y con el apoyo del flamante virrey, el archiduque Alberto. Tales discrepancias se profundizaron mucho más con la oposición que mostró el padre Gracián al nuevo método de gobierno (denominado la "Consulta"76) que, a partir de 1585, había impuesto Doria para gobernar la Orden77. Desde las Constituciones de 1581, hechas en el Capítulo de Alcalá de Henares para separar a los carmelitas descalzos de los calzados, no se realizó ningún trabajo profundo sobre la legislación de la reforma hasta el capítulo celebrado en Madrid en 1590, donde el padre Doria quiso articular sus innovaciones dándole fuerza constitucional ${ }^{78}$.

Ante el control que el monarca hispano quería mantener sobre la reforma descalza de los carmelitas, Clemente VIII tomó una decisión trascendental, crear la Congregación de San Elías en Italia, independientemente de la llamada Congregación de San José de España79. A partir de treinta religiosos carmelitas que había en Italia, Clemente VIII los dio por buenos para iniciar su andadura paralelamente a los de España ${ }^{80}$. El 20 de marzo de 1597, el Pontífice extendía una serie de breves por los que eximía a los conventos de Roma de la jurisdicción de los Superiores hispanos, al mismo tiempo que los ponía bajo la inmediata dirección de la Santa Sede, les autorizó a tener novicios y a participar de los mismos privilegios y gracias que ya poseían los conventos españoles. Finalmente, Clemente VIII encargó al cardenal Pinelli que se hiciera cargo de los nuevos conventos de Roma y que estableciera las Constituciones para esta nueva obediencia ${ }^{81}$.

espíritu de llama, coord. Otger Steggink, (Roma: Institutum Carmelitanum, 1991), pp. 270 y 274; El pensamiento religioso en Secundino Castro, "Aproximación al pensamiento religioso de Teresa", Revista de Espiritualidad, 41, (1982), pp. 63-80.

75 Peregrinación de Anastasio. Diálogo III, Obras, III, pp. 98-104. Sobre el enfrentamiento entre Gracián y Doria, Hipólito de la Sagrada Familia, "Le conflit Doria-Gratien, Etude historicojuridique", Etudes Carmélitaines, 15, (1946), pp. 196-273; Sobre el interés de los portugueses por crear conventos carmelitas, Efrén de la Madre de Dios y Otger Steggink, Tiempo y vida de San Juan de la Cruz, (Madrid: BAC, 1993), pp. 660-661.

76 Hipólito de la Sagrada Familia, "La Consulta. Estudio histórico-jurídico", El Monte Carmelo, 77, (1969), pp. 181 y ss.

77 Efrén de la Madre de Dios y Otger Steggink, Tiempo y vida de San Juan de la Cruz, pp. 764774.

78 Constituciones Carmelitarum Discalceatorum 1567-1600, (Roma-Paris: DescléeTeresianum, 1968), pp. 303-376.

79 Silverio de Santa Teresa, Historia del Carmen Descalzo en España, Portugal y América, (Burgos: Monte Carmelo 1937), vol. VIII, p. 1.

${ }^{80}$ AGS, E, leg. 731.

${ }^{81}$ Isidoro de San José, Historia Generalis Fratrum Discalceatorum, I, lib. I, cap. XXIV. El duque de Sesa, embajador español en Roma, daba noticia al rey de estas decisiones tomadas por el Pontífice en carta, fechada el 5 de mayo (AGS. E, leg. 364). 
La difusión del Carmelo, después de la muerte de santa Teresa (1582), en Francia, se produjo después que el caballero franco-español Juan de Quintanadueñas de Bréthiny llegase a Sevilla, donde descubrió la descalcez, y trabó amistad con María de san José, que se perfilaba como la sucesora de Teresa, y le pidiese que fundara en Francia ${ }^{82}$. La traducción al francés de las obras de santa Teresa, realizada por Quintanadueñas, facilitó el intento ${ }^{83}$. La idea fue seguida por un grupo de clérigos y seglares parisinos (doctor Gallemant, André Duval, Pierre Bérulle, Dom Beaucousin, san Francisco de Sales), sobre todo Mme d'Acarie, la futura María de la Encarnación ${ }^{84}$. El problema que pronto se planteó fue la obediencia que debían de seguir (la hispana o la romana) los nuevos conventos, por eso, si la doctrina y el pensamiento de Teresa de Jesús fuero muy bien recibidos, a la hora de fundar conventos, la cuestión estuvo muy parada durante los primeros años.

Ana de Jesús, que no entendía de jurisdicciones sino de vivencias religiosas, se dio cuenta muy pronto y escribía a fray Diego de Guevara:

"Esta primavera tendremos aquí nuestros frailes descalzos de Roma, llamados de sus Altezas y deseados destas tierras. Antes que los pidiéramos de acá, los había mandado su Santidad viniesen a fundar aquí y a Francia. Viene por mayor, el padre fray Tomás de Jesús, con recados del Papa y del Padre Vicario General de nuestra orden. Darán la obediencia estos conventos. Nosotras jamás nos apartaremos de España y hemos escrito a nuestro padre General ordene lo que quiere que hagamos que, en dejando aquí gobierno de la orden, no podemos ir sin escrúpulo de que aflojara lo comenzado que está muy impreso en las que hemos recibido y en pocos años se fundará aquí"85. Poco tiempo después insistía en el mismo tema: "que ya hemos procurado lo que se os ha confesado de tener breve de Su Santidad para que los prelados de Italia no nos puedan estorbar el volver a España las que venimos cuando pareciere a cada una, ni los de allá a ir al convento donde profesamos. Por todas lo procuré antes de dar la obediencia. Dímosla en presencia del

\footnotetext{
82 Sobre María de San José, Escritos Espirituales, edita Simeón de la Sagrada Familia, (Roma: Tipografia Poliglotta Vaticana, 1979); Las páginas que le dedica Anselmo Donazar, Principio y fin de una reforma, (Bogotá: Guadalupe 1968), pp. 323 y ss.; Ildefonso Moriones, Ana de Jesús y la herencia teresiana: ¿Humanismo cristiano o rigor primitivo?, (Roma: Teresiannum, 1968), pp. 101-119.

83 Michel Houssaye, M. de Bérulle et les Carmelites de France, 1575-1611, (Paris: E. Plon, 1872); Jean Dagens, Bérulle et les origines de la Restauration catholique (1575-1611), (Paris: Desclée, 1952) ; Pierre Sérouet, Jean Brétigny (1556-134). Aux origines du Carmel de France, de Belgique et du Congo, (Louvain: 1974).

84 Bruno de Jésus Marie, La belle Acarie, bienheureuse Marie de I'Incarnation, (Paris: 1942).

85 Carta fechada en Bruselas, el 15 de enero 1610; Concepción Torres, Ana de Jesús. Cartas (1590-1521). Religiosidad y vida cotidiana en la clausura femenina del Siglo de Oro, (Salamanca: Ediciones Universidad de Salamanca, 1995), p. 85.
} 
nuncio, después de que el padre fray Tomás de Jesús con cinco religiosos que trae consigo, había fundado su convento en esta ciudad"86.

Las dificultades que atravesaban las carmelitas españolas eran cada vez más fuertes y Ana de Jesús era consciente de que su actividad en Flandes había finalizado: "... mas no se puede en este estado, aun nos limitan el dar limosnas. Muchas les han hecho aquí a nuestros Descalzos [se refiere a los de Italia] y en Francia bien los aceptan en estas tierras. Y harto querríamos fundaciones de nosotras, mas el nuevo General de Italia no sé cómo lo determinará, que comienza con tanta prudencia que le he escrito si no se ha de fundar más, no tenemos qué hacer acá"87. El padre Jerónimo Gracián discrepaba de las ideas de Ana de Jesús como lo escribía a María de San José: "En lo que toca a nuestros negocios muchas cosas ha echado de ver la madre Ana en que se ha errado en estas fundaciones de aquí y, tratándolas conmigo, le digo las verdades, aunque sin instancia, no más que parecer seco. Las sus monjas prioras bien andan deseosas de seguir lo que les dijere, mas siempre ando huyendo de que no parezca que les aparto de su parecer de ella", al mismo tiempo que se hacía eco de esta división jurisdiccional de las carmelitas descalzas: "De Roma he sabido que el Papa hace no sé qué congregación de Descalzos Carmelitas para dilatar la fe". En 1610, afirmaba que estaban esperando a "los Padres que vienen de Roma a gobernar a estas monjas". Una vez que las carmelitas se decantaron por la obediencia de Roma, la expansión de los conventos tanto en Francia como en Flandes se llevó con rapidez.

Lo sorprendente del caso es que la infanta Isabel Clara Eugenia se decantó por el Carmelo dependiente de Roma y no por el de España, lo que la hacía conectar con las ideas pacifistas y misioneras que pretendía el papado, lo que permite entender que la Gobernadora de Flandes compartiese los ideales espirituales que defendía Roma y de las formas en que se debía realizar su expansión. La implicación fue tan comprometida que la Infanta ayudó económicamente a la fundación de la Congregación Propaganda Fide e, incluso, patrocinó algunas de las misiones del recién fundado dicasterio; asimismo, desde la corte flamenca, envió numerosos religiosos a Roma para que se formaran como futuros misioneros de Propaganda Fide, que después regresaban a Flandes para organizar las misiones en las fronteras con los herejes $^{88}$. Este es el caso del P. Nicolás Jansenio, en 1623, favorecido por la infanta Isabel para que le preparasen como misionero de Propaganda Fide,

\footnotetext{
${ }^{86}$ Carta fechada en Bruselas el 21 de septiembre 1610, Ibidem, p. 91.

${ }^{87}$ Ibidem, p. 95.

88 Alexandre Pasture, La restauration religieuse aux Pays-Bas Catholiques, (Louvain: Librairie Universitaire, 1924), pp. 315-328 ; Cordula Van Wyhe, "Piety and Politics in the Royal Convent of discalced carmelita nuns in Brussels (1607-1646)", Revue d'Histoire Ecclésiastique de Belgique, 100, (2005), pp. 457-487, http://dx.doi.org/10.1484/j.rhe.3.98; Eddy Put, "Les archiducs et la réforme catholique: champs d'action et limites politiques", en Albert and Isabella Essays, eds., Werner Thomas y Luc Duerloo, (Louvain/Bruxelles/Turnhout: Musées royaux d'art et d'histoire, 1998), pp. 256-257.
} 
siendo el encargado después de todas las misiones de Propaganda Fide en el Reino de Dania (Noruega) ${ }^{89}$. Es decir, que la Infanta prefería a los misioneros que le enviaba Propaganda Fide en vez de los que venían del territorio hispano.

No es de extrañar el interés de Isabel Clara Eugenia en Propaganda Fide si se tiene en cuenta el estrecho vínculo que tuvo dicha mujer con dos personas de su corte, y que resultan ser clave para entender los orígenes de Propaganda Fide.

El P. Gracián había sido el compañero de Santa Teresa de Jesús en el momento de fundar el Carmelo descalzo. A la muerte de la Santa, Jerónimo Gracián quiso continuar el gobierno de la orden reformada siguiendo las disposiciones y el carisma de Teresa de Jesús; no obstante, tras dejar de ser el primer provincial fue expulsado de los carmelitas descalzos por su oposición a la forma de gobernar del P. Nicolás Doria. La negativa de Gracián de apoyar la creación de un nuevo órgano de gobierno para la orden reformada, conocido como la "Consulta"90, que colocaba a la Orden bajo un control más directo del monarca hispano, le valió a Gracián el recelo de Felipe II, quien acabó apoyando su expulsión de la orden descalza. Este apoyo del monarca a su salida de la Orden sirvió también para complacer al P. Doria y a su linaje de prestamistas genoveses del rey ${ }^{91}$. El P. Gracián decidió entonces entrar en el Carmelo de antigua observancia, dejando atrás la descalcez, y aceptando la proposición de los Archiduques de acompañar al embajador español en Bruselas, don Felipe Folch de Cardona, marqués de Guadaleste, hasta la corte flamenca, de la que nunca más se movió. No obstante, Clemente VIII insistió en varias ocasiones a Gracián para que volviera al carmelo descalzo, hasta el punto de expedirle el breve de readmisión a la descalcez en 1592, sugiriéndole que entrara en la descalcez de la congregación italiana. En mi

\footnotetext{
89 "Ho con ogni efficaccia raccomandato il P. Nicolò Jansenio favorito da V.A. con le lettere delli 9 di novembre passato alla Congregatione di Propaganda Fide, e spero che riceverà ogni sodisfattione non solo perche I'accoglienza di V.A. con questi Signori Cardinali grandemente prevale, ma ancora perche il detto Padre ha molto merito con la medessima Congregatione per le fatiche fatte nella visita del Regno di Dania. Io poi che non disidero altro che di socorrere V.A. in tutte l'occasioni che mi si rappresentano, posso assicurarla che farò per il detto Padre ogni possibile diligenza acciochè resti pienamente gratificato". ASPF, Lettere Volgari 2, 16221623 , fol. 63v, Carta de Propaganda a la serenísima infanta Isabel de Flandes. Roma, a 11 de febrero de 1623.

90 Señalaba Gracián: "Y viéndome entonces con comisión apostólica del cardenal Alberto, envié un fraile al Papa y al Protector de la Orden para que examinasen este nuevo modo de gobierno de la Consulta, y escribí y declare a muchos los grandes inconvenientes que de allí se habían de seguir". En P. Silverio de Santa Teresa, O.C.D., Historia del Carmen Descalzo en España, Portugal y América, (Burgos: Monte Carmelo, 1937), tomo VIII, p. 299; P. Hipólito de la Sagrada Familia, O.C.D., "La Consulta. Estudio histórico-jurídico", Monte Carmelo, 77, (1969), pp. 153-189.

91 Giorgio Doria, "Consideraciones sobre las actividades de un "factor cambista" genovés al servicio de la corona española", en Dinero y crédito (siglos XVI al XIX), ed., Alfonso Otazu, (Madrid: Moneda y crédito, 1978), pp. 279-293; Silvano Giordano y Claudio Paolocci, Nicolò Doria. Itinerari economici, culturali, religiosi nei secoli XVI-XVII tra Spagna, Genova e I'Europa, (Génova: Associazione Amici della Biblioteca Franzonniana, 1996), 2 vols.; Felipe Ruiz Martín, "Las finanzas españolas durante el reinado de Felipe II", Cuadernos de historia anexos a la revista Hispania, 2, (1968), p. 138.
} 
opinión, la insistencia de Clemente VIII para que Jerónimo Gracián regresara a la descalcez estaba relacionada con la creación de la primera Congregación de Propaganda Fide, necesitando del sentido misional del que Gracián siempre hizo gala en su vida y en sus escritos. Sin embargo, Gracián nunca volvió a la descalcez porque prefirió actuar desde la libertad de acción que disfrutó en la corte de Bruselas, dado que los descalzos españoles no mostraban interés en las misiones. Por su parte, Clemente VIII, ante la negativa del P. Gracián de regresar a la descalcez y sobre todo la rotunda oposición que el Pontífice encontró en los superiores españoles del Carmelo descalzo para colaborar con la creación del dicasterio, llevó a que el papa Aldobrandini dividiera el Carmelo descalzo en dos ramas; una española y otra italiana bajo las órdenes del pontífice romano. Mientras los descalzos italianos se dedicaron a las misiones, los reformados españoles, seguiría su propia evolución centrada únicamente en la perfección del espíritu y la oración. El interés de Clemente VIII en contar con Jerónimo Gracián para organizar las misiones pone de manifiesto sus mismos proyectos e ideales, y desde la corte de Bruselas, junto a los Archiduques, Gracián nunca dejó de colaborar con la incipiente Propaganda Fide. Tanto fue así, que Gracián solicitó insistentemente a Roma, también por medio de la infanta Isabel Clara Eugenia, dando mayor peso al asunto, la presencia de los carmelitas italianos en el norte de Europa, consiguiendo que en 1607 llegara el primer grupo de misioneros descalzos a Flandes donde fundaron su primer convento en los Países Bajos, y desde el cual organizaron la expansión del carmelo descalzo por el norte de Europa, desde donde también trataban de cruzar a Inglaterra ${ }^{92}$.

Además de Jerónimo Gracián, la presencia de Juan Bautista Vives en la corte de Bruselas resulta clave para entender el vínculo de la corte flamenca con los cardenales de Propaganda Fide. Monseñor Vives, familiar del humanista Juan Luis Vives, fue un clérigo valenciano (1545-1632) que trabajó como agente diplomático de la infanta Isabel Clara Eugenia en Roma. Juan Bautista Vives fue el fundador del colegio de Propaganda Fide en Roma, donde estudiaban los misioneros que debían después extender el catolicismo romano por el mundo. Tenemos pocas referencias sobre este clérigo, y desde luego escasas en cuanto a su labor en la corte de Bruselas junto a la infanta Isabel Clara Eugenia. Pero fue precisamente en la década de 1620 cuando las cartas que envió a los cardenales de Propaganda Fide le sitúan en Bruselas. Y desde allí, antes de viajar a Roma, se empeñó en dar origen al Colegio de Propaganda Fide favoreciendo la creación de la primera sede oficial de la institución recién fundada ${ }^{93}$. Así, los cardenales tendrían un lugar de reunión

\footnotetext{
92 El mismo P. Gracián señalaba las diferencias entre los descalzos españoles y los italianos: "La Congregación de los carmelitas descalzos de Italia, que, aunque es la misma orden que la de España, tienen diversos prelados y en alguna manera, siguen diverso espíritu, porque con celo se dan a la conversión de las almas, como se ha visto en los que fueron a Persia". P. Silverio de Santa Teresa, O.C.D., Historia del Carmen, pp. 14-15.

93 Giuseppe Piras, La Congregazione e il collegio di Propaganda Fide di H. H. Vives, G. Leonardi e M. de funes, (Roma: Università Gregoriana Editrice, 1976).
} 
que sirvió también para formar a los misioneros. Desde marzo de 1624 la correspondencia de Vives desde Bruselas con Propaganda Fide fue continua. No sólo se interesó por un buen lugar para la sede, comprando el céntrico palacio Ferratini en la piazza della Trinità, sino que además quiso beneficiar económicamente al colegio para que desde un principio entrara un buen número de futuros misioneros a los que formar. Para dotar económicamente al colegio, Vives escribió a Madrid para que, con el consentimiento de Felipe IV, pudiera donar los beneficios económicos de una Abadía que existía en Calabria, que eran de Patronato Regio, y otros beneficios eclesiásticos que dicho eclesiástico poseía94. Por si hubiera alguna resistencia desde la corte madrileña, y para mayor respaldo a la iniciativa de Vives, los cardenales de Propaganda Fide no dudaron en expedir un breve en el que daban facultad a Vives para donar todos sus bienes eclesiásticos para el gobierno y la buena dirección de Propaganda Fide ${ }^{95}$. Finalmente, ante la duda de si monseñor Vives conseguiría los beneficios de la abadía de Calabria, pronto se despejó con el consentimiento de Felipe IV, logrando así esquivar las restricciones de un Patronato Regio que comenzaba a ceder ante la presión cada vez mayor de Propaganda Fide.

El 3 de febrero de 1628, la colaboración de monseñor Vives -con el respaldo de la infanta Isabel Clara Eugenia- con Propaganda Fide llegó a su punto más álgido, cuando Vives propuso desde Bruselas solucionar el gran problema que acompañó a Propaganda Fide durante muchas décadas: la manera de conseguir más dinero para financiar la actividad apostólica del dicasterio. La propuesta de Vives trataba de recaudar dinero aplicando la décima en todas las donaciones, legados, testamentos y últimas voluntades que iría destinado a las misiones de la Congregación ${ }^{96}$. Sólo se aplicaría la décima en aquellas herencias o donaciones que excedieran a los mil escudos. Esta propuesta revolucionaria fue rechazada rápidamente por los propios cardenales de Propaganda Fide, negándose todos, quienes veían que la actividad de Propaganda debía ir poco a poco, sin enfrentarse a los poderes políticos y a unas Monarquías, como la hispana, que todavía veían con desconfianza la entrada de misioneros enviados por Propaganda a sus territorios de ultramar.

\footnotetext{
94 "Monsignore Vives non solamente vuol dare al collegio erigendo la casa c'ha comprato per la sua habitatione, ma ancora lo vul dotare, perche li collegiati si possino mantenere fin a un buon numero, et non contento di darli tutta la sua robba temporale che possede, et aquistara mentre viva, disegna ancora darli entrata ecclesiastica, et fin adesso ha fatto diligenze in Spagna, per haver il consenso di sua Maestà per unirci un Abbatia che tienen in Calabria di patronato Reggio. Ancora vuol gravare, per tempo di 20 anni di pensione, alcuni beneficii ecclesiastici che possede". Roma, 26 de marzo de 1624. ASPF, SOCG 384, Memoriali del 1624 ed ultimi sei mesi del 1623, fol. 238r,

95 "N. S. ha concesso a Monsignore Vives per un breve, faculta di testar de tutti li suoi beni, con una restrictiva solamente a favore del collegio erigendo. Il quale et tutta la sua robba debbi stare sotto la protettione, governo, et direttione della Sacra congregatione de Propaganda Fide". APF, SOCG 384, Memoriali del 1624 ed ultimi sei mesi del 1623, f. $247 r$. Roma, 26 de marzo de 1624.

96 ASPF, SOCG 388, Memoriali anno 1628, fol. 32r.
} 
Hay que tener en cuenta que Vives colaboró con la fundación de Propaganda Fide teniendo en cuenta los problemas religiosos que afectaban especialmente a Flandes, es decir, parece que el plan del clérigo era el de fundar un Colegio de Propaganda Fide que formase a los misioneros en cuestiones teológicas, de modo que combatiesen la herejía en misiones al norte de Europa. No obstante, los cardenales de Propaganda Fide y el propio Gregorio XV, a pesar de que aceptaron gustosamente la ayuda de Vives, tenían un proyecto más universal, que incluía misiones apostólicas en todos los territorios de ultramar, ya fuera de Oriente u Occidente.

En cuanto a la colaboración directa de la infanta Isabel Clara Eugenia con Propaganda Fide es preciso analizar algunos ejemplos más, para entender hasta qué punto fue promotora de la Congregación y la importancia de esta mujer, que desde Bruselas actuó como intermediaria entre las cortes de Madrid y Roma. Por estos años, la influencia y la desconfianza del conde duque de Olivares en la Congregación, convierte a la corte de Flandes en un lugar de mediación entre Propaganda Fide y la Monarquía Hispana. Misioneros de América llegaban a la corte de Bruselas - paradójicamente no a la de Madrid como correspondería- pidiendo a la infanta que les patrocinara ante la Congregación de Propaganda Fide para conseguir que mandaran más misioneros al Nuevo Mundo. Es el caso del misionero portugués Domenico Coelho, provincial de la Compañía de Jesús en Brasil que acude a Bruselas para que la infanta Isabel pidiera más ayuda para sus misiones a Propaganda Fide, lo cual demuestra la influencia de esta mujer sobre el dicasterio cardenalicio ${ }^{97}$. Más interesante resultó el enfado de la infanta Isabel Clara Eugenia con la corte madrileña, el 17 de julio de 1627, ante la falta de financiación de la corte de Madrid al colegio inglés de jesuitas de Douai, en Flandes, que preparaba a misioneros dispuestos a viajar a Inglaterra sin vacilar ante el martirio que les esperaba. El problema vino por la falta de financiación de este colegio de seminaristas ingleses, tal y como escribía la infanta al nuncio en Flandes ${ }^{98}$, que desde su fundación en 1568 velaba por la conversión al catolicismo de la vecina Inglaterra, y que había dado desde un total de 111 mártires católicos a la Iglesia Católica. Un año antes, Propaganda había escrito al marqués de Leganés por este mismo asunto para que informara a Olivares, pero no se había obtenido ninguna respuesta por parte del valido, que no le interesaba ayudar económicamente al colegio. Por si fuera poco, la insistencia de Roma a la infanta debido a este motivo, encendía

97 "Venido dal Brassil il P. Domenico Coelho provincial della compagnia di Giesù del Brasil, per alcuni gratie, lui domanderà a V. Santità per servitio e consolatione di quei cattolici di qual Regno cosi lontano, supplica che sia ben visto, e spedito con sua sodisfattione attestado che'l detto padre è persona di valor, e di merito, e che in tutti li cariche della religione s'è portato bene". ASPF, SOCG 129, Lettere di Francia, Fiandra, Spagna, Indie, Inghilterra ed Ibernia 1627, vol. IV, f. 35r, Carta de la infanta Isabel desde Bruselas a Propaganda, 10 de enero de 1627.

98 La deuda de los ministros del rey según Propaganda ascendía a 21.253 florines. El carmelita descalzo Domenico de la Scala escribía a la Infanta para insistirle por el mismo motivo. ASPF, Lettere volgari $6,1627, \mathrm{ff} .81 \mathrm{r}, 102 \mathrm{v}$, cartas al nuncio de Flandes y a la infanta Isabel. Roma, a 17 de julio de 1627 . 
más, si cabe, el enfado de Isabel Clara Eugenia. Un año antes, monseñor Vives, en octubre de 1626, había conseguido que el propio pontífice Urbano VIII contribuyera a la financiación del colegio de Douai en Flandes, que se encontraba en muy mal estado, con la consiguiente queja del Papado porque la corte madrileña parecía que sólo tenía dinero para la guerra y los ejércitos en Flandes, olvidándose de contribuir con los misioneros que eran realmente los que frenaban, a golpe de conversión, según la infanta y el Papado, el avance de los herejes ${ }^{99}$. Ciertamente la comunicación de la infanta Isabel Clara Eugenia con Propaganda Fide sobre este asunto de Douai pasaba por manos del P. Domingo de Jesús María Ruzola, carmelita descalzo español que estaba en Roma formando parte de la congregación descalza italiana "San Elias". El P. Domingo de Jesús cambió su nombre por el de Domenico della Scala, por residir en el convento de la Scala desde 1604. El convento de la Scala había sido fundado por Clemente VIII en 1600 para formar teológicamente a reformadores y misioneros ${ }^{100}$. En 1622, este carmelita descalzo, el P. Domenico della Scala, fue de los principales promotores de la fundación de Propaganda Fide por Gregorio XV, colaborando con el dicasterio al encargarse de la recaudación de las limosnas de Propaganda. Por tanto, la relación de la Infanta con Propaganda Fide no se limitaba solamente al contacto con los cardenales, sino que también se comunicó con carmelitas descalzos que estaban al servicio de Propaganda Fide. El P. Domenico desde Propaganda Fide tramitaba la ida de carmelitas descalzos de la rama italiana a Flandes. Cabe añadir que, finalmente, tras la insistencia de la infanta a la corte madrileña llegaría la ayuda al colegio de Douai.

\section{Reacciones en la corte de Felipe IV a la fundación del dicasterio apostólico}

Apenas fundada Propaganda Fide en 1622, una de las primeras acciones fue escribir desde Roma a los nuncios para prevenir cualquier sospecha 0 reacción contraria por parte de los poderes políticos ${ }^{101}$. Fechadas el 17 de enero de 1622 se enviaban las cartas a todas las nunciaturas para que dieran aviso a sus majestades católicas de que trece cardenales y dos prelados iban a componer una Congregación que se reuniría asiduamente, al menos dos veces al mes, para velar por la evangelización y por el éxito de las misiones católicas ${ }^{102}$. En este sentido, el dicasterio puso especial cuidado en la reacción

\footnotetext{
99 "Ancora la persecutione è maggiore che sia stata mai, et il Rè per sovenir li suoi bisogni di guerra non volendolo aiutar li stati, è stato aconsigliato, che confischi li beni alli cattolici, et la esecutione e tanto rigorosa, che non li lasciano altro che qualche portano in dosso", ASPF, SOCG 386, Memoriali dell'anno 1626, fol. 495r, 5 de octubre de 1626.

100 P. Silverio de Santa Teresa, O.C.D., Obras de fray Jerónimo Gracián, (Burgos: Monte Carmelo, 1933), tomo III, pp. 1-114.

101 Eutimio Sastre Santos, "La Circolare dei Nunzi comunica la fondazione di Propaganda Fide, 15 gennaio 1622", Ius Missionale, 1, (2007), pp. 151-186.

102 ASPF, Lettere Volgari 2, 1622-1623, fol. 5r. Giovanni Pizzorusso, "La congregazione romana "de propaganda fide" e la duplice fedeltà dei missionari tra monarchie coloniali e universalismo
} 
por parte de la corte madrileña temiendo alguna resistencia a fundar un organismo romano encargado de las misiones, como había ocurrido durante el siglo XVI, no obstante, esta vez, resultó favorable. El 31 de marzo de 1621 Felipe IV comenzaba a reinar, permitiendo a los pocos años el ascenso del conde duque de Olivares a lo más alto de la cúspide de gobierno. Desde esta posición, Olivares rechazó la forma de gobierno del anterior reinado, los valimientos de Lerma y de Uceda, cuyas políticas exteriores, a ojos de Olivares, habían debilitado el poderío español de tiempos de Felipe $\mathrm{II}^{103}$. La actividad de Propaganda Fide y sus intereses universales se enfrentaban a los proyectos de Olivares sobre los dominios españoles. Por lo que, si la fundación de Propaganda fue aceptada por la Monarquía fue por dos motivos: primero porque la Monarquía obligó a Propaganda Fide a que al menos un cardenal de la congregación fuera español y otro filoespañol (siendo el primer cardenal español el cardenal-protector Gaspar de Borja) ${ }^{104}$, de manera que, desde dentro del dicasterio, Olivares esperaba tener influencia, pero no fue así; y en segundo lugar, porque el Papado tenía importantes promotores de Propaganda Fide en la corte madrileña. El principal de ellos, sin duda ninguna, fue el cardenal infante Fernando, hermano menor del monarca, quien desde un principio mostró su apoyo a la Congregación.

En la corte, el cardenal infante se rodeó de servidores que mantuvieron una fluida relación con el papado. Desde su infancia, el infante Fernando estuvo bajo el cuidado de la familia de los Borja, concretamente de las condesas de Lemos y de Altamira, nietas de san Francisco de Borja y hermanas del duque de Lerma ${ }^{105}$. Ambas mujeres, durante el reinado de Felipe III se mostraron favorables a los intereses religiosos y políticos del papado, tratando de solucionar los pleitos de jurisdicción eclesiástica que años antes habían enfrentado a la Monarquía con la Santa Sede ${ }^{106}$. Por eso, cuando se pidió a Roma que nombrara cardenal al niño infante, de tan sólo diez años de edad, el pontífice apoyó sin problemas la decisión, a pesar de la corta edad del infante. De la casa del Cardenal Infante, haciéndose pública el 12 de junio de 1622, influyeron de manera decisiva en la carrera del cardenal infante dos personas, hijos de la condesa de Altamira, don Melchor Moscoso (camarlengo del cardenal infante) y don Antonio Moscoso (gentilhombre de cámara), contrarios a la política olivarista ${ }^{107}$. Otras personas del entorno del cardenal infante que influyeron en las decisiones de Fernando, y que formaron parte de su casa fueron: don Pedro Fernández Navarrete, secretario de cámara;

pontificio (XVII secolo)", Librosdelacorte, Monográfico 1, año 6, (2014), on line https://revistas.uam.es/librosdelacorte/article/view/1632

103 John Elliot, El conde-duque de Olivares, (Barcelona: Crítica, 2009), pp. 435-455.

104 La división de los territorios que debía velar cada cardenal aparece detallada en la primera reunión de Propaganda. ASPF, Acta 3, 1622-1625, fol. 1.

105 Quintín Aldea Vaquero, El cardenal infante don Fernando o la formación de un príncipe de España, (Madrid: RAH, 1997), p. 23.

106 ASV, Segreteria di Stato Spagna, 50, fols. 304r-305v, Carta del nuncio Camillo Caetano al cardenal Aldobrandini. Barcelona, 19 de julio de 1599.

107 Quintín Aldea Vaquero, España y Europa en el siglo XVII. Correspondencia de Saavedra Fajardo, (Madrid: CSIC-RAH, 2008), tomo III, vol.1, pp. 20-24. 
Cristóbal de Guzmán, maestro del infante; Juan de San Martín, músico de la capilla real que daba lecciones de música a don Fernando; el jesuita Jerónimo Florencia que fue su confesor; y el Marqués de Malpica su mayordomo mayor.

En la relación que el Cardenal Infante mantuvo con el papado, resulta desconocido su interés por la recién fundada Congregación de Propaganda Fide, que explicaría el firme apoyo político y económico que este dicasterio encontró en la corte madrileña, frente al recelo del valido Olivares que desconfiaba de las intenciones del organismo romano. Destaca, por tanto, la continua financiación del cardenal infante para la sustentación y proyección de Propaganda Fide. Ciertamente, una de las principales preocupaciónes de Propaganda Fide fue la financiación de sus misiones. Durante las primeras reuniones del dicasterio, entre todas las propuestas que los trece cardenales propusieron para encontrar financiación, triunfó la del cardenal Cobelluzio, quien sugirió recaudar dinero de la donación del valor de los anillos cardenalicios. El 8 de marzo de 1622 se acordaba en acta que los anillos cardenalicios, valorados en 500 escudos de oro, serían donados para el funcionamiento de Propaganda ${ }^{108}$. A los pocos meses, el cardenal Ottavio Bandini escribía al nuncio en Madrid, Innocenzo Massimo, para que insistiera a los cardenales españoles para que pagaran rápido, como ya habían hecho los cardenales italianos, ${ }^{109}$ al mismo tiempo que solicitaba la colaboración del cardenal infante para que donara los 500 escudos por su anillo en obra tan importante ${ }^{110}$.

La respuesta del cardenal infante Fernando no se hizo esperar, siendo el primer cardenal español en colaborar con un total de 4.000 escudos por su anillo (ocho veces más que la cantidad solicitada) a lo que añadió 1.621 escudos como limosna para la Congregación ${ }^{111}$. El apoyo económico del cardenal infante a Propaganda Fide iba más allá de sus frecuentes donaciones. El 26 de marzo de 1626, el cardenal infante escribía al cardenal Bandini de Propaganda para informarle de la venida de un grupo de carmelitas descalzos italianos, venidos de la misión de Persia, con los que se había reunido y mostraba su satisfacción por la labor apostólica que estaban realizando en Persia, como misioneros de Propaganda Fide, a los que apoyaría y financiaría en sus misiones:

\footnotetext{
108 ASPF, Acta 3, 1622-1625, fols. 5v-6r.

109 "Per recapitarle alli cardinali spagnoli che conforme alla mente di N. Signore et all'essempio di quasi tutti li cardinali italiani si disposero a pagar in vita li loro anelli cardinalicii". ASPF, Lettere Volgari 2, 1622-1623, fol. 55r, carta de Propaganda Fide al nuncio en España. Roma, 28 de enero de 1623.

110 "Potrà tentar la magnanima liberalità del signore Cardinal Infante, acciò che conforme alla sua grandezza in questo superi come conviene aiutti gl'altri". ASPF, Lettere Volgari 2, 16221623, fol. 55r, carta de Propaganda Fide al nuncio en España. Roma, 28 de enero de 1623.

111 "Ho vivamente operato nel negotio dell'assignamento che ha fatto S.S. dell'annello cardinalitio alla congregatione di propaganda fide, et da questo serenisimo infante ho ottenuto a tale effetto quattro milla scudi, e qui aggionta ne viene la polizza". En ASPF, SOCG 189. Lusitania, India, Japonia 1629, fol. 24r; Las limosnas que ofreció el cardenal infante en ASPF, Stato Temporale dal 1622 al 1639, fol. 49r. Nuncio al cardenal Bandini, Madrid 25 enero 1623.
} 
"Illmo y Rmo Señor. Los padres carmelitas descalços que han venido de la mision de Persia me dieron la carta de V.S. escrita en nombre de la Sagrada Congregaçión de Propaganda Fide, y juntamente me hiçieron relación de los grandes frutos spirituales que por medio de su predicaçión se consiguen en aquellos reynos de que tuve interior y exterior alegría, viendo que entre los infieles se abre la puerta a la verdadera y Catholica religión. La obra es muy digna de ser ayudada y así de mi parte procuraré se façiliten los intentos a que han venido a España, como lo podrá asegurar V.S. a la Sagrada Congregaçión"112.

Su interés por la expansión de los carmelitas descalzos de la rama italiana -en ningún caso la española- continuó cuando se marchó a gobernar Flandes en el año 1630, apoyando nuevas fundaciones de estos religiosos como había hecho años antes su tía, la infanta Isabel Clara Eugenia, cuando era gobernadora de los Países Bajos.

No sólo el cardenal infante apoyó la fundación de Propaganda, sino que hubo destacados nobles de la corte de Felipe IV que apoyaron las misiones promovidas por el dicasterio. Todos ellos del entorno del cardenal infante. Este era el caso del III duque de Feria, don Gómez Suárez de Figueroa y Córdoba, por entonces gobernador de Milán, quien colaboró con Propaganda protegiendo a un grupo de misioneros que llegaban a Madrid para persuadir al monarca hispano de que financiara sus misiones ${ }^{113}$. Otro miembro del círculo del cardenal infante que favoreció la actividad de Propaganda Fide en sus primeros años fue don Diego Mejía, el marqués de Leganés, destacado general de la milicia en Flandes y en Italia ${ }^{114}$. El Marqués fue protagonista indiscutible junto al cardenal infante de la victoria de Nördlinghen en 1634, que simbolizó la unión de ambas ramas de la dinastía de los Austria contra las tropas suecas ${ }^{115}$. En 1626 , el cardenal Ludovisi, encargado de las misiones de Flandes, escribía al marqués de Leganés para que mediara a la hora de conseguir una ayuda económica de la corte madrileña para que el colegio de

\footnotetext{
112 ASPF, SOCG, Lettere riferite l'Anno 1626, vol. 101, fol. 65r, carta del cardenal infante al señor cardenal Bandini. Madrid, 26 de marzo de 1626.

113 ASPF, Lettere Volgari 2, 1622-1623, fol. 90v.

114 Pascual Gayangos y Arce, "Cartas de algunos PP. de la Compañía de Jesús sobre los sucesos de la Monarquía entre los años de 1634 y 1648", en Memorial Histórico Español: colección de documentos, opúsculos y antigüedades de la RAH, (Madrid: Imprenta Nacional, 1863), vol. XVII, p. 7.

115 Fernando Checa Cremades y Jesús Sáenz de Miera, "La corte española y la pintura de Flandes", en El Real Alcázar de Madrid: dos siglos de arquitectura y coleccionismo en la corte de los reyes de España, ed., F. Checa Cremades, (Madrid: Nerea, 1994), pp. 232-234; Mary Crawford Volk, "Rubens in Madrid and the Decoration of the King's summer apartments", The Burlington Magazine, 123, (1982), pp. 513-529; Víctor Mínguez, Los reyes solares: iconografía astral de la Monarquía Hispánica, (Castellón de la Plana: Universitat Jaume I, 2001), pp. 299300.
} 
ingleses de Douai pudiera continuar, por la extrema necesidad en la que se encontraba ${ }^{116}$.

De esta manera, en el entorno del cardenal infante Fernando se fue creando un grupo de ministros y servidores que compartían un mismo sentido de obediencia al Pontífice, manteniendo un estrecho contacto con los cardenales que formaban la congregación de Propaganda Fide y colaborando con los objetivos del dicasterio. No existió, por tanto, ninguna relación entre la recién fundada Propaganda Fide y el valido de Felipe IV, no existe documentación, y si la Congregación necesitaba convencer a Olivares (bien a que contribuye económicamente con alguna limosna o a que enviara algún misionero, o ayudara a la fundación de un colegio de Propaganda en territorio de la Monarquía) en ningún caso escribía directamente a Olivares. Éste debía ser persuadido por los consejeros cercanos al cardenal infante Fernando o por la presión directa de la infanta Isabel Clara Eugenia.

En este sentido, es preciso explicar que el cardenal infante continuó favoreciendo a la congregación apostólica cuando se marchó a los Países Bajos como gobernador en 1634. Y es que allí, en Bruselas, la infanta Isabel Clara Eugenia había hecho de su corte un bastión de Propaganda Fide, desde el que apoyar económicamente y con misioneros al dicasterio, por lo que el cardenal infante continuó la labor de su tía la infanta Isabel ${ }^{117}$.

Sin duda alguna, Propaganda Fide fue aceptada en la corte madrileña porque la infanta Isabel Clara Eugenia presionó, desde Bruselas, con gran empeño, para que los ministros y el propio Felipe IV apoyaran desde Madrid la fundación del nuevo dicasterio. La correspondencia que mantuvo esta infanta con los cardenales de la congregación romana es muy frecuente y se muestra siempre servicial a este respecto, hasta tal punto, que a veces su implicación con las misiones apostólicas de Propaganda, le llevó a enfrentarse con los intereses de la política de Olivares.

\section{La Congregación para la Propaganda Fide y el Regio Patronato Universal}

La Congregación de Propaganda no cuestionaba el mismo derecho patronal, sino algunas facetas de su interpretación. Es decir, el patronato se justificaba y tenía razón de ser en cuanto que servía al propósito de la institución. De aquí, al principio de un patronato limitado a aquellos territorios en donde

116 ASPF, SOCG 129, Lettere di Francia, Fiandra, Spagna, Indie, Inghilterra ed Ibernia 1627, vol. 4: fol. 176r, carta del nuncio Patriarca de Antiochia al Cardenal Ludovisi. Madrid, 16 de noviembre de 1626.

117 Werner Thomas, "La corte de Bruselas y la restauración de la casa de Habsburgo en Flandes (1598-1633). Una revisión historiográfica", en El arte en la corte de los archiduques Alberto de Austria e Isabel Clara Eugenia (1598-1633). Un reino imaginado, (Madrid: Sociedad Estatal para la conmemoración de los centenarios de Felipe II y Carlos V, 1999), pp. 46-63. 
efectivamente podía ser eficaz había un solo paso. Durante la larga gestación del asunto de la iglesia del Japón que se trató durante varios años en las Juntas misionales de Madrid, se fue delineando en la curia romana otro principio sobre la extensión del patronato, el rey tenía el privilegio de ejercer sus derechos patronales solo en aquellos territorios en los cuales conservaba su dominio temporal efectivo, o sea, un patronazgo verdaderamente funcional. Con esta idea, la Congregación de Propaganda trató de evitar reconocer al rey derechos patronales en el Japón, en donde no había tenido un poder temporal. En 1634, el secretario Ingoli hacía una declaración en la que decía que el Papa estaba decidido a no conceder al Rey Católico el nombramiento de obispos en territorios no ocupados por él como monarca hispano y portugués ${ }^{118}$.

Si el principio de limitada extensión del patronato cundía para todas las misiones de Oriente, Propaganda lo aplicó de un modo más decidido a las misiones de China, hacia la cual mostró desde el principio particular predilección ${ }^{119}$.

En la larga gestación de los Vicarios Apostólicos con el Rey Católico, soberano de las Monarquías hispana y portuguesa, con el fin de despojar la obra misional del control político y mantener una Iglesia independiente del Regio Patronato, Propaganda creyó haber encontrado la solución en los obispos in partibus, esto es, prelados decorados con el carácter episcopal que pudieran proveer a la fundación de una iglesia local con la ordenación de sacerdotes nacionales. Jurídicamente, el nombramiento de estos obispos in partibus, no siendo obispos residenciales, no estaba sujeto al derecho de patronato $y$, por ello, podían ser libremente nombrados por el Papa ${ }^{120}$. En 1655 aparece el proyecto de enviar a las Indias Occidentales obispos in partibus para la China y "reinos adyacentes". El proyecto fue confirmado en la Congregación particular del 29 julio 1657 en donde se decidió mandar tres obispos in partibus con facultad de vicarios apostólicos. Esto se llevó a cabo al año siguiente en las personas de Francisco Pallu, con el título de obispo in partibus de Heliopolis, de Pedro Lambert de la Motte, con el título de obispo in partibus de Berito y, en 1660, en la persona de Ignacio Cotolendi con el título de obispo in partibus de Metellópolis, a los que se les encomendó los territorios de Indochina y China en calidad de vicarios apostólicos ${ }^{121}$. En las letras pontificias no se encuentra ningún elemento que pueda esclarecer la

\footnotetext{
${ }^{118}$ Ignacio Ting Pong Lee, "La actitud de la Sagrada Congregación frente al Regio Patronato", p. 390.

119 Jean Beckmann, "La Congrégation de la Propagation de la Foi face à la politique internationale", Neue Zeitschrift für Missionswissenschaft/Nouvelle Revue de sciences missionnaires, 19, (1963), pp. 241-271.

${ }^{120}$ Acta Sacrae Congregationis de Propaganda Fide, vol. 8, fol. 210. Así lo defendía, Andrés Andreucci, Hierarchia ecclesiastica, (Roma: 1746), pp. 12-15.

${ }_{121}$ Adrien Launay, documents historiques relatifs à la societè des missions étranger, (Roma: Librairie Orientale et Américaine, 1904), vol. I, pp. 24-26; Natale Loda, "La missione, il codex canonum ecclesiarum orientalium (cceo) e la sede apostolica", Iura Orientalia, 6, (2010), pp. 123-161.
} 
posición de estos vicarios apostólicos frente al regio patronato, pero las instrucciones que Propaganda dio a los vicarios apostólicos en 1659 puede esclarecer algo: que en el viaje se evitase pasar por lugares sujetos a los portugueses; se precisaba que Macao u otros lugares que obedecen al rey de Portugal estaban sujetos a los vicarios. En cuanto tuvo conocimiento el rey de Portugal del asunto mostró sus reticencias ${ }^{122}$.

Tampoco fue del agrado de la Monarquía católica la institución de los vicariatos apostólicos en Oriente. En 1669, el marqués de Astorga y San Ramón, embajador español en Roma, presentó un memorial al papa. En él, señalaba que la Monarquía se gastaba anualmente 500 mil escudos anuales en las misiones de China, Japón, Filipinas y Formosa. Y "porque de nombrar obispos y vicarios apostólicos con jurisdicción que no sean vasallos de su Majestad se seguiría grandísimo prejuicio a la conversión, pudiéndose fácilmente crear competencia de naciones" suplicaba al pontífice ordenase a la Congregación de Propaganda Fide proveyera "para que los obispos o vicarios apostólicos que tuvieren de ir a las partes de China, Japón, Isla Hermosa y demás islas vecinas sean de la misma nación que son los misioneros que el dicho Rey sustenta"123.

La Congregación Propaganda Fide ponía bajo el Pontífice la expansión de la Iglesia, evitando la utilización de la religión para favorecer los intereses de las Monarquías y su expansión. La fundación de la Congregación de la Propaganda Fide sin duda iba dirigida para contrarrestar la actividad misionera del Regio Patronato. Por eso cuando el Colector de Portugal se enteró de su fundación, propuso que se instituyeran dos delegaciones en Madrid y Lisboa, respectivamente ${ }^{124}$. En su camino la Propaganda Fide se atravesó con el Regio Patronato.

En 1588, Roma ya se había opuesto al proyecto de la conquista de China que el padre Alonso Sánchez trajo desde Filipinas. A partir de entonces, la vigilancia de los pontífices para que la Monarquía católica no realizase ninguna conquista fue una constante, recordada a los diferentes nuncios en Madrid a través de sus instrucciones ${ }^{125}$. En 1625, el dominico Diego Collado llegaba a Roma, enviado por los mendicantes del Japón, a discutir la causa a

122 Charles R. Boxer, the portuguese sea-borne Empire, 1415-1825, (London: Hutchinson of London, 1969), pp. 220-230; António da Silva Rego, Le Patronage Portugais de I'Orient, un aperçu Historique, (Lisboa: Agencia Geral do Ultramar, 1957); Pius Malekandathil, "Cross, Sword and Conflicts: A Study of the Political Meanings of the Struggle between the Padroado Real and the Propaganda Fide", Studies in History, 27, (2011), pp. 251-267.

${ }^{123}$ Acta Congregationis Particulares de rebus Sinarum et Indiarum Orientalium, vol. 1a, fol. 258 .

${ }^{124}$ Giovanni Pizzorusso, "Il padroado régio portoghese nella dimensione 'globale' della Chiesa romana. Note storico-documentarie con particolare riferimento al Seicento" in Gli archivi della Santa Sede come fonte per la storia del Portogallo in età oderna. Studi in memoria di Carmen Radulet, coord. Giovanni Pizzorusso, Gaetano Platania, Matteo Sanfilippo, (Viterbo: Settecittà, 2012), pp. 177-219.

125 Giovanni Pizzorusso, "Per servitio della Sacra Congregatione de Propaganda Fide': i nunzi apostolici e le missioni tra centralità romana e Chiesa universale (1622-1660)", Cheiron, 30, (1998), pp. 201-227. 
favor de la libertad de acción en las misiones de Japón ${ }^{126}$. Trajo un prolijo memorial para la Congregación de Propaganda Fide que proponía remedios para los problemas de aquella iglesia, sujeta a persecución por los ataques de ingleses y holandeses. Propaganda se percató de que algunos puntos propuestos en el memorial, tocaban de lleno en el derecho del Regio Patronato. El monarca formó una Junta, compuesta por representantes de las órdenes religiosas afectadas, para que le informaran de la situación y de las soluciones propuestas. Las decisiones de la Junta fueron aprobadas por el Consejo de Indias, pero también pasó por el Consejo de Portugal. Las resoluciones concedían a los jesuitas la exclusiva de misión en el Japón por veinte años. Conforme con el ello, el rey envió una carta a Urbano VIII (16 junio 1628) para que extendiera las bulas correspondientes que confirmaran estas decisiones ${ }^{127}$.

No obstante, los documentos enviados por el monarca hispano pasaron a la Congregación de la Propaganda y vieron que tales medidas iban en contra con el espíritu misionero para todas las órdenes religiosas, que movía a la Congregación. Ingoli manifestó al papa la contradicción que existía y urgió para que el nuncio en Madrid, el cardenal Pamphili, convenciese al monarca sobre el asunto ${ }^{128}$. Tras numerosas órdenes contradictorias, el rey ordenó reunir una Junta que, el 17 de diciembre de 1631, se reunía para ratificar lo que decía Roma. Según lo aprobado en la Junta, se preparó en Roma la minuta del documento pontificio que debía expedirse en forma de breve, que fue revisado y corregido hasta que aprobado por la Congregación, el 24 de enero de 1633, fue enviado a Felipe IV para obtener su aprobación y extender el breve. Pero fue aquí donde la Congregación de la Propaganda se encontró con las dificultades y oposición de la corte de Madrid ${ }^{129}$. Dos fueron los obstáculos que encontró Roma a la aceptación del breve por parte de la Monarquía: en primer lugar, se utilizó el exequatur o pase regio. Los del Consejo de Castilla exigieron que el breve viniera por vía diplomática; es decir, por medio del embajador de España en Roma y no a través del nuncio de Madrid, como Roma había hecho. En segundo lugar (y más importante) el Consejo denunció que el documento no hacía mención que la expansión misionera había sido a instancias del Rey Católico, lo que ya había previsto Roma, esto es, que el rey de España perdía su condición de patrono promotor de la expansión misionera. Finalmente, se envió el original y el Consejo aprobó el breve, justamente cuando la flota partía para Indias, en el mes de abril 1634.

\footnotetext{
126 Line Pedot, La S. C. de Propaganda Fide e le missioni del Giappone (1622-1838), (Vicenza: Tipografia Pont. Vesc. S. Giuseppe, 1942), cap. 10.

127 Esther Jiménez Pablo, "El papel de fray Diego Collado al servicio de Propaganda Fide en las Indias orientales", Libros de la Corte.es, 4, (2016), pp. 153-163.

128 Ibidem, pp. 132-142.

129 Ignacio Ting Pong Lee, "La actitud de la Sagrada Congregación frente al Regio Patronato", en Josef Metzler, (dir.), Sacrae Congregationis de Propaganda Fide. Memoria rerum, (Roma: 1972), vol. I/1, pp. 363-364.
} 
A partir de entonces, Roma se percató de la falta de libertad en la expansión misionera y puso a la Sagrada Congregación ante una realidad que no podía ignorar: que no le era posible tomar ninguna iniciativa en el campo misional sin contar con el monarca hispano. El secretario Ingoli propuso -en la Congregación particular de 9 de febrero de 1634- o renunciar a las misiones a través de la Monarquía católica para no sancionar las imposiciones de Madrid o avenirse a las pretensiones del Consejo de Indias. A este dilema, la Congregación propuso dos soluciones: convencer a los consejeros del rey mediante un agente de la propaganda que iría a Madrid o soslayar a Madrid y Lisboa y hacer la expansión misionera independientemente; ahora bien, si se seguía esta última vía como parece que se propugnaba, el problema consistía en sufragar la cantidad de gastos que conllevaba el transporte y manutención de los misioneros a tierras tan lejanas. Así pues, la Propaganda tuvo que enfrentarse al problema del patronato real y de admitirlo a su $\operatorname{pesar}^{130}$.

\section{Conclusión}

Religiosos como Gracián, Vives, Domenico della Scala, y destacados nobles como el duque de Feria o el marqués de Leganés, así como miembros de la familia real como el cardenal infante Fernando, la infanta Isabel Clara Eugenia, el archiduque Alberto, formaron una red que unía a la corte de Madrid con la de Bruselas, y éstas a su vez, con la Congregación de Propaganda Fide. Además de unirles una amistad, compartían unos mismos ideales y proyectos que permitieron esquivar poco a poco los obstáculos, o si se prefiere, la aparente falta de interés del principal ministro del rey, el conde duque de Olivares, a quien su política de expansionismo le hizo involucrarse en numerosas guerras que evitaron una mayor atención a la creación de un nuevo dicasterio romano. Propaganda Fide se fue fortaleciendo con el tiempo y fue capaz de emprender una lucha "pacífica", a través de los misioneros, con el Consejo de Indias y el Patronato Regio por recuperar los derechos y privilegios sobre la evangelización de las Indias.

130 Antonio Egaña, "La función misionera del poder civil según Juan Solórzano Pereira (15751655)", Studia Missionalia VI, (Roma: Facultate Missiologiae in Pont. Universitatis Gregoriana, 1951), pp. 69-113. 
Bibliografía

Acta Congregationis Particulares de rebus Sinarum et Indiarum Orientalium, vol. 1a, fol. 258 r.

Aldea Vaquero 1997; Quintín Aldea Vaquero, El cardenal infante don Fernando o la formación de un príncipe de España, (Madrid: RAH, 1997).

Aldea Vaquero 2008: Quintín Aldea Vaquero, España y Europa en el siglo XVII. Correspondencia de Saavedra Fajardo, (Madrid: CSIC-RAH, 2008), tomo III, vol.1.

Andreucci 1746: Andrés Andreucci, Hierarchia ecclesiastica, (Roma: 1746).

Beckmann 1963: Jean Beckmann, "La Congrégation de la Propagation de la Foi face à la politique internationale", Neue Zeitschrift für Missionswissenschaft/Nouvelle Revue de sciences missionnaires, 19, (1963), pp. 241-271.

Bentivoglio 1807: Memorie del Cardinal Bentivoglio, (Milán: 1807), vol. IV.

Boxer 1969: Charles R. Boxer, the portuguese sea-borne Empire, 14151825, (London: Hutchinson of London, 1969), pp. 220-230.

Broggio 2013: Paolo Broggio, "Teologia 'romana' e universalismo papale: la conquista del mondo (secoli XVI-XVII)", en M. Antonietta Visceglia (coord), Papato e politica internazionale nella prima età moderna, (Roma: Viella, 2013), pp. 441-477.

Bullarium Pontificium S. C. de Propaganda Fide, (Romae: 1839), vol. I.

Carro 1951: Venancio Carro, La Teología y los teólogos juristas españoles ante la conquista de América, (Salamanca: PPC, 1951)

Castañeda: Paulino Castañeda Delgado, La teocracia pontifical y la conquista de América, (Vitoria: Editorial Eset, 1968).

Castro 1982: Secundino Castro, "Aproximación al pensamiento religioso de Teresa", Revista de Espiritualidad, 41, (1982), pp. 63-80.

Collectanea S. Congregationis de Propaganda fidei seu Decreta, Instructiones, Rescripta pro Apostolicis Missionibus ex Tabulario e eiusdem Sacrae Congregationis deprompta (Roma: 1893), vol. I.

Colunga 1915: Emilio Colunga, "Intelectualistas y místicos en la teología española del siglo XVI", Ciencia Tomista, 10, (1915), pp. 223-242. 
Constituciones Carmelitarum Discalceatorum 1567-1600, (Roma-Paris: Desclée-Teresianum, 1968).

Costa 1997: Cosme Jose Costa, A missiological conflict between Padroado and Propaganda in the East, (Goa: Pilar Publications, 1997).

Crawford 1982: Mary Crawford Volk, "Rubens in Madrid and the Decoration of the King's summer apartments", The Burlington Magazine, 123, (1982), pp. 513-529.

Cruz 1966: Carmelo de la Cruz, "La reforma teresiana instrumento de la reforma de Trento", El Monte Carmelo, 74, (1966), pp. 311-339.

Chaline 1999: Olivier Chaline, "La bataille de la Montagne Blanche (8 novembre 1620). Un mystique chez les guerriers, (Paris: Editions Noesis, 1999).

Chapoulie 1943 : Henri Chapoulie, Aux origines d'une église. Rome et les Missions d'Indochine au XVIIe siècle (París: Bloud \& Gay, 1943), vol. I.

Checa Cremades, Saenz de Miera 1994: Fernando Checa Cremades y Jesús Sáenz de Miera, "La corte española y la pintura de Flandes", en El Real Alcázar de Madrid: dos siglos de arquitectura y coleccionismo en la corte de los reyes de España, ed., F. Checa Cremades, (Madrid: Nerea, 1994), pp. 220-235.

Dagens 1952: Jean Dagens, Bérulle et les origines de la Restauration catholique (1575-1611), (Paris: Desclée, 1952).

Donazar 1968: Anselmo Donazar, Principio y fin de una reforma, (Bogotá: Guadalupe 1968).

Doria 1978: Giorgio Doria, "Consideraciones sobre las actividades de un "factor cambista" genovés al servicio de la corona española", en Dinero y crédito (siglos XVI al XIX), ed., Alfonso Otazu, (Madrid: Moneda y crédito, 1978), pp. 279-293.

Egaña 1951: Antonio Egaña, "La función misionera del poder civil según Juan Solórzano Pereira (1575-1655)", Studia Missionalia VI, (Roma: Facultate Missiologiae in Pont. Universitatis Gregoriana, 1951).

Egaña 1958: Antonio Egaña, La teoría del regio vicario español en Indias, (Roma: Analecta Gregoriana, 1958).

Elliot 2009: John Elliot, El conde-duque de Olivares, (Barcelona: Crítica, 2009). 
Essen 1924: Leon van der Essen, Correspondence d'Ottavio Mirto Frangipani. Premier nonce de Flande (1596-1606), (Roma-Paris-Bruxelles: 1924).

García-Gallo 1957-58: Alfonso García-Gallo y de Diego, "Las Bulas de Alejandro VI y el ordenamiento jurídico de la expansión portuguesa y castellana en África e Indias", Anuario Historia del Derecho Español, 27-28, (1957-58), pp. 462-829.

Gayangos y Arce 1863: Pascual Gayangos y Arce, "Cartas de algunos PP. de la Compañía de Jesús sobre los sucesos de la Monarquía entre los años de 1634 y 1648", en Memorial Histórico Español: colección de documentos, opúsculos y antigüedades de la RAH, (Madrid: Imprenta Nacional, 1863), vol. XVII.

Giménez Fernández 1944: Manuel Giménez Fernández, Nuevas consideraciones sobre la historia, sentido y valor de las bulas alejandrinas de 1493 referentes a las Indias, (Sevilla: Escuela de Estudios HispanoAmericanos de la Universidad de Sevilla, 1944).

Giordano 2003: Silvano Giordano, Le istrutioni generali di Polo V ai diplomatici pontifici, 1605-1621, (Tübingen: Max Niemeyer Verlag, 2003), vol. I.

Giordano, Paolocci 1996: Silvano Giordano y Claudio Paolocci, Nicolò Doria. Itinerari economici, culturali, religiosi nei secoli XVI-XVII tra Spagna, Genova e I'Europa, (Génova: Associazione Amici della Biblioteca Franzonniana, 1996), 2 vols.

Gracián 1586: Jerónimo Gracián, Estímulo de la propaganda de la Fe y vínculo y hermandad entre los padres descalzos del Carmen y san Francisco, (Lisboa: 1586, reimpreso en Bruselas 1609).

Gracián 1905: Jerónimo Gracián, Peregrinación de Anastasio, (Burgos: Monte Carmelo, 1905).

Green 1945: Otis Howard Green, Vida y obras de Lupercio Leonardo de Argensola, (Zaragoza: Institución Fernando el Católico, 1945).

Gutiérrez García-Brazales 1983: Manuel Gutiérrez García-Brazales, "El Consejo de la Gobernación del Arzobispado de Toledo", Anales Toledanos 16, (1983), pp. 63-138.

Hinojosa 1896: Ricardo de Hinojosa, Los despachos de la diplomacia pontificia en España, (Madrid: B.A. de la Fuente, 1896).

Houssaye 1872: Michel Houssaye, M. de Bérulle et les Carmelites de France, 1575-1611, (Paris: E. Plon, 1872) 
Jaitner 1997: Klaus Jaitner, Die Hauptinstruktionen Gregors XV. Für die nuntien und gesandten an den Europâischen Fürstenhöfen 1621-1623, (Tübingen: Max Niemeyer Verlag, 1997), vol. I.

Jesús María 1773: Juan de Jesús María, Historia Missionum Carmelitanum Discalceatorum, en Opera Omnia ejusdem, (Florencia: 1771-1774), vol. III, cap. III.

Jesús María 1919: El venerable P. Juan de Jesús María, III General de la Congregación de Italia: su vida, sus virtudes y sus escritos, (Burgos: Monte Carmelo, 1919).

Jésus Marie 1942: Bruno de Jésus Marie, La belle Acarie, bienheureuse Marie de l'Incarnation, (Paris: 1942).

Jiménez Pablo 2016: Esther Jiménez Pablo, "El papel de fray Diego Collado al servicio de Propaganda Fide en las Indias orientales", Libros de la Corte.es, 4, (2016), pp. 153-163.

Kowalsky 1956: Nikolaus Kowalsky, Pontificio Collegio Urbano de Propaganda Fide, (Tivoli: Tip. A. Chicca, 1956).

Launay 1904: Adrien Launay, documents historiques relatifs à la societè des missions étranger, (Roma: Librairie Orientale et Américaine, 1904), vol. I.

Leturia 1930: Pedro Leturia, Las grandes bulas misionales de Alejandro VI, (Barcelona: Bibliotheca hispana missionum, 1930, vol. I).

Loda 2010: Natale Loda, "La missione, il codex canonum ecclesiarum orientalium (cceo) e la sede apostolica", Iura Orientalia, 6, (2010), pp. 123161.

Madre de Dios, Steggink 1993: Efrén de la Madre de Dios y Otger Steggink, Tiempo y vida de San Juan de la Cruz, (Madrid: BAC, 1993).

Malekandathil 2011: Pius Malekandathil, "Cross, Sword and Conflicts: A Study of the Political Meanings of the Struggle between the Padroado Real and the Propaganda Fide", Studies in History, 27, (2011), pp. 251-267.

Manzano 1941: Juan Manzano Manzano, "El sentido misional de la empresa de Indias", Revista de Estudios Políticos, 1, (1941), pp. 108-114.

Manzano 1948: Juan Manzano Manzano, La incorporación de las Indias a la Corona de Castilla, (Madrid: Ediciones Cultura Hispánica, 1948).

Manzano 1950: Juan Manzano Manzano, Historia de las recopilaciones de Indias, (Madrid: Ediciones Cultura Hispánica, 1950), pp. 34-39. 
Marcocchi 1981: Massimo Marcocchi, Colonialismo, cristianesimo e culture extraeuropee. La istruzione di Propaganda Fide ai vicari apostolici dell'Asia orientale (1659), (Milán: Jaca Book, 1981).

Martínez Hernández 2011: Santiago Martínez Hernández, "Reyna esclarecida, Cynthia clara, hermosa luna: el aprendizaje político y cortesano de la infanta Isabel Clara Eugenia", en Isabel Clara Eugenia. Soberanía femenina en las cortes de Madrid y Bruselas, coord. Cordula Van Wyhe, (Madrid: CEEH, 2011), pp. 20-59.

Metzler 1972: Josef Metzler, "Francesco Ingoli, der erste Secretar der Kongregation (1578-1649)", en Josef Metzler (dir.), Sacrae Congregationis de Propaganda Fide. Memoria rerum, (Roma: 1972), vol. I/1, pp. 197-243.

Metzler 2000: Josef Metzler, "La Congregazione «de Propaganda Fide» e lo sviluppo delle missioni cattoliche (ss. XVIII al XX)", Anuario Historia de la Iglesia, 9, (2000), pp. 145-154.

Millán 1994: José Martínez Millán (dir.), La Corte de Felipe II, (Madrid: Alianza, 1994).

Millán 1999: José Martínez Millán, "La emperatriz María y las pugnas cortesanas en tiempos de Felipe II", en Ernest Belenguer Cebriá, Felipe II y el Mediterráneo, (Madrid: 1999), III, pp. 143-163.

Millán 2015: José Martínez Millán, "La reforma espiritual de Santa Teresa de Jesús y sus relaciones con las facciones cortesanas", Hispania Sacra 67, (2015), pp. 429-466.

Millán, Conti 2005: José Martínez Millán y Santiago Fernández Conti (dirs.), La Monarquía de Felipe II. La Casa del Rey, (Madrid: Mapfre, 2005), II vols.

Millán, Visceglia 2005: José Martínez Millán, M. Antonietta Visceglia (dirs.), La Monarquía de Felipe III, (Madrid: Mapfre, 2005), 4 vols.

Mínguez 2001: Víctor Mínguez, Los reyes solares: iconografía astral de la Monarquía Hispánica, (Castellón de la Plana: Universitat Jaume I, 2001), pp. 299-300.

Moriones 1968: Ildefonso Moriones, Ana de Jesús y la herencia teresiana: ¿Humanismo cristiano o rigor primitivo?, (Roma: Teresiannum, 1968).

Niño Jesús 1923: Florencia del Niño Jesús, La Orden de Santa Teresa, la fundación de la Propaganda Fide y las Misiones Carmelitanas, (Madrid: Tip. Nieto, 1923). 
Pasture 1924: Alexandre Pasture, La restauration religieuse aux Pays-Bas Catholiques, (Louvain: Librairie Universitaire, 1924).

Paventi 1943: Saverio M. Paventi, "Origo Congregationis Urbanianae super facultates missionariorum", Commentarium pro Religiosis et Missionariis, 24, (1943), pp. 288-300.

Paventi 1952: Saverio M. Paventi, "Congregazione Urbaniana super facultatibus missionariorum", Studia missionalia, 7, (1952), pp. 217-240.

Pedot 1942: Line Pedot, La S. C. de Propaganda Fide e le missioni del Giappone (1622-1838), (Vicenza: Tipografia Pont. Vesc. S. Giuseppe, 1942).

Pereña 1970: Luciano Pereña de la obra de Juan Roa Dávila, De regnorum iustitia, (Madrid: CSIC, 1970).

Piepper 1922: Carl Piepper, Die Propaganda. Ihre Entstehung und religiöse Bedeutung, (Aachen, Immensee: Xaveriusverlagsbuchh, 1922).

Piras 1976: Giuseppe Piras, La congregazione eil collegio di propaganda fide di J. B. Vives, G. Leonardi e M. De funes, (Roma: Università Gregoriana, 1976).

Pizzorusso 1998: Giovanni Pizzorusso, "Per servitio della Sacra Congregatione de Propaganda Fide': i nunzi apostolici e le missioni tra centralità romana e Chiesa universale (1622-1660)", Cheiron, 30, (1998), pp. 201-227.

Pizzorusso 2008: Giovanni Pizzorusso, "Il papato e le missioni extraeuropee nell'epoca di Paolo V. Una prospettiva di sintesi", en Alexander Koller (ed.), Die Außenbeziehungen des Römischen Kurie unter Paul V. Borghese (16051621), (Tübingen: Max Niemeyer Vlg., 2008), pp. 367-390.

Pizzorusso 2012: Giovanni Pizzorusso, "Il padroado régio portoghese nella dimensione 'globale' della Chiesa romana. Note storico-documentarie con particolare riferimento al Seicento" in Gli archivi della Santa Sede come fonte per la storia del Portogallo in età moderna. Studi in memoria di Carmen Radulet, coord. Giovanni Pizzorusso, Gaetano Platania, Matteo Sanfilippo, (Viterbo: Settecittà, 2012), pp. 177-219.

Pizzorusso 2014: Giovanni Pizzorusso, "La congregazione romana "de propaganda fide" e la duplice fedeltà dei missionari tra monarchie coloniali e universalismo pontificio (XVII secolo)", Librosdelacorte, Monográfico 1, año 6, (2014), https://revistas.uam.es/librosdelacorte/article/view/1632

Prodi 2011: Paolo Prodi, El soberano pontífice, un cuerpo y dos almas: la Monarquía papal en la primera Edad Moderna, (Madrid: Akal, 2011). 
Put 1998: Eddy Put, "Les archiducs et la réforme catholique: champs d'action et limites politiques", en Albert and Isabella Essays, eds. Werner Thomas y Luc Duerloo, (Louvain/Bruxelles/Turnhout: Musées royaux d'art et d'histoire, 1998), pp. 256-257.

Raviola 2008: Blythe Alice Raviola, "La imagen de la infanta Catalina Micaela en la correspondencia de los gobernadores piamonteses", en Las Relaciones Discretas ente las Monarquías Hispana y Portuguesa. Las Casas de las Reinas, coords. José Martínez Millán y Maria Paula Marçal Lourenço, (Madrid: Polifemo, 2008), vol. III, pp. 1733-1747.

Raviola, Varallo 2013: Blythe Alice Raviola y Franca Varallo, L'Infanta Caterina d'Austria, duchessa di Savoia (1567-1597), (Roma: Carocci Editore, 2013).

Río Barredo 2003: María José del Río Barredo, "De Madrid a Turín: el ceremonial de las reinas españolas en la corte ducal de Catalina Micaela de Saboya", Cuadernos de Historia Moderna, 97, (2003), Anejo II, pp. 97-122.

Rodríguez 1611: Emmanuel Rodríguez, Nova collectio et Compilatio privilegiorum Regularium Mendicatium et non Mendicatum, (Venetiis: 1611).

Ruiz Martín 1968: Felipe Ruiz Martín, "Las finanzas españolas durante el reinado de Felipe II", Cuadernos de historia anexos a la revista Hispania, 2, (1968), pp. 109-173.

Sagrada Familia 1946: Hipólito de la Sagrada Familia, "Le conflit DoriaGratien, Etude historico-juridique", Etudes Carmélitaines, 15, (1946), pp. 196-273.

Sagrada Familia 1969: Hipólito de la Sagrada Familia, "La Consulta. Estudio histórico-jurídico", El Monte Carmelo, 77, (1969), pp. 153-189.

San José 1979: María de San José, Escritos Espirituales, edita Simeón de la Sagrada Familia (Roma: Tipografia Poliglotta Vaticana, 1979).

Sánchez 1961: José Sánchez, Academias literarias del siglo de oro español, (Madrid: Gredos, 1961).

Santa María 1644: Francisco de Santa María, Reforma de los Descalços de Nuestra Señora del Carmen de la primitiva Observancia, (Madrid: por Diego Diaz de la Carrera, 1644).

Santa Teresa 1933: P. Silverio de Santa Teresa, O.C.D., Obras de fray Jerónimo Gracián, (Burgos: Monte Carmelo, 1933), tomo III. 
Santa Teresa 1937: P. Silverio de Santa Teresa, O.C.D., Historia del Carmen Descalzo en España, Portugal y América, (Burgos: Monte Carmelo, 1937), tomo VIII.

Santísimo Sacramento 1952: Tarsicio del Santísimo Sacramento, "Los Carmelitas Descalzos y la Sagrada Congregación de Propaganda Fide", El monte Carmelo, 60, (1952), pp. 37-68.

Sastre 2007: Eutimio Sastre Santos, "La Circolare dei Nunzi comunica la fondazione di Propaganda Fide, 15 gennaio 1622", Ius Missionale, 1, (2007), pp. 151-186.

Sérouet 1974: Pierre Sérouet, Jean Brétigny (1556-134). Aux origines du Carmel de France, de Belgique et du Congo, (Louvain: 1974).

Silva Rego 1957: António da Silva Rego, Le Patronage Portugais de I'Orient, un aperçu Historique, (Lisboa: Agencia Geral do Ultramar, 1957).

Steggink 1991: Otger Steggink, "Observancia y Descalcez carmelitana: reforma romano-tridentina y «reforma» (española) del Rey: un conflicto y su primera víctima", en San Juan de la Cruz, espíritu de llama, coord. Otger Steggink, (Roma: Institutum Carmelitanum, 1991), pp. 270 y 274.

Thomas 1999: Werner Thomas, "La corte de Bruselas y la restauración de la casa de Habsburgo en Flandes (1598-1633). Una revisión historiográfica", en El arte en la corte de los archiduques Alberto de Austria e Isabel Clara Eugenia (1598-1633). Un reino imaginado, (Madrid: Sociedad Estatal para la conmemoración de los centenarios de Felipe II y Carlos V, 1999), pp. 46-63.

Ting Pong 1972: Ignacio Ting Pong Lee, "La actitud de la Sagrada Congregación frente al Regio Patronato", en Josef Metzler, (dir.), Sacrae Congregationis de Propaganda Fide. Memoria rerum, (Roma: 1972), vol. I/1, pp. 363-364.

Tormo 1917: Elías Tormo, En las Descalzas Reales de Madrid. Estudios históricos, iconográficos y artísticos, (Madrid: Sociedad Estatal para la Conmemoración de los Centenarios de Felipe II y Carlos V, 1917), pp. 153177.

Torres 1948: Pedro Torres, La Bula Omnimoda de Adriano VI, (Madrid: Instituto Santo Toribio de Mogrovejo, 1948).

Torres 1995: Concepción Torres, Ana de Jesús. Cartas (1590-1521). Religiosidad y vida cotidiana en la clausura femenina del Siglo de Oro, (Salamanca: Ediciones Universidad de Salamanca, 1995). 
Varallo 1992: Franco Varallo, De Nizza a Torino. I festeggiamenti per il matrimonio di Carlo Emanuele I e Catalina d'Austria, (Turín: Centro Studi Piemontesi, 1992).

Wythe 2005: Cordula Van Wythe, "Piety and Politics in the Royal Convent of discalced carmelita nuns in Brussels (1607-1646)", Revue d'Histoire Ecclésiastique de Belgique, 100, (2005), pp. 457-487, http://dx.doi.org/10.1484/j.rhe.3.98 